\title{
New insights into the role of TREM2 in Alzheimer's disease
}

\author{
Maud Gratuze ${ }^{1,2,3}$, Cheryl E. G. Leyns ${ }^{1,2,3}$ and David M. Holtzman ${ }^{1,2,3^{*}}$
}

\begin{abstract}
Alzheimer's disease (AD) is the leading cause of dementia. The two histopathological markers of AD are amyloid plaques composed of the amyloid- $\beta$ (A $\beta$ ) peptide, and neurofibrillary tangles of aggregated, abnormally hyperphosphorylated tau protein. The majority of AD cases are late-onset, after the age of 65 , where a clear cause is still unknown. However, there are likely different multifactorial contributors including age, enviornment, biology and genetics which can increase risk for the disease. Genetic predisposition is considerable, with heritability estimates of $60-80 \%$. Genetic factors such as rare variants of TREM2 (triggering receptor expressed on myeloid cells-2) strongly increase the risk of developing $A D$, confirming the role of microglia in $A D$ pathogenesis. In the last 5 years, several studies have dissected the mechanisms by which TREM2, as well as its rare variants affect amyloid and tau pathologies and their consequences in both animal models and in human studies. In this review, we summarize increases in our understanding of the involvement of TREM 2 and microglia in AD development that may open new therapeutic strategies targeting the immune system to influence AD pathogenesis.
\end{abstract}

Keywords: Alzheimer's disease, Neurodegeneration, TREM2, ApoE, Microglia, Gliosis

\section{Background}

Alzheimer's disease (AD) was first described more than a century ago by the German neuropsychiatrist, Dr. Alois Alzheimer ([1], English translation [2]), and today is the leading cause of dementia worldwide [3-5]. In the United States, deaths attributed to AD have increased by $71 \%$ between 2000 and 2013, ranking this disease as the 6th leading cause of death [6]. Although symptoms can vary greatly from one patient to another, $\mathrm{AD}$ results in progressive memory loss and irreversible cognitive decline. The two histopathological markers of $\mathrm{AD}$ are extracellular amyloid plaques composed of the amyloid- $\beta$ peptide $(A \beta)$, and neurofibrillary tangles (NFTs) within neurons derived from abnormally aggregated, hyperphosphorylated tau protein [3-5]. These defining protein aggregates are accompanied by synaptic and neuronal loss.

In addition to protein aggregation, neuroinflammatory changes are present in $\mathrm{AD}$ brains, including alterations in the morphology, activation and distribution of microglia and astrocytes (microgliosis and astrogliosis) as well as

\footnotetext{
* Correspondence: holtzman@wustl.edu

${ }^{1}$ Department of Neurology, St. Louis, USA

${ }^{2}$ Hope Center for Neurological Disorders, St. Louis, USA

Full list of author information is available at the end of the article
}

increased expression of inflammatory mediators [7-9]. However, the exact contributions of both microgliosis and astrogliosis in $\mathrm{AD}$ are not clear. While first hypothesized to contribute to $\mathrm{AD}$ neuropathology, gliosis and neuroinflammation seem to have more complex effects and could be either beneficial or damaging in those with $\mathrm{AD}$ (for review [10]). For example, reactive microglia and astrocytes can contribute to the clearance of $A \beta$ [11-13]. Conversely, the production of pro-inflammatory cytokines like TNF $\alpha$ (Tumor necrosis factor $\alpha$ ) or IL1- $\beta$ (Interleukin $1 \beta$ ) resulting from glial activation are harmful and toxic to neurons (for review [14, 15]). Many studies also suggest that neuroinflammation exacerbates tau phosphorylation [16-18]. Altogether, these data suggest the possibility that gliosis and neuroinflammation have neuroprotective roles early in $\mathrm{AD}$ by controlling amyloid load, but later can become toxic to neurons and act as a catalyst for neurodegeneration.

Recent genomic studies have identified several novel genetic risk factors linking neuroinflammation and $A D$. Highly penetrant mutations in APP, PSEN1, and PSEN2 are known to cause rare, autosomal dominant AD, where individuals develop the disease in mid-life [19]. However, the majority of $\mathrm{AD}$ cases are sporadic and late-onset, the causes of which are still unknown. Late-onset AD (LOAD)

(C) The Author(s). 2018 Open Access This article is distributed under the terms of the Creative Commons Attribution 4.0 International License (http://creativecommons.org/licenses/by/4.0/), which permits unrestricted use, distribution, and 
seems to be multifactorial, with age, environmental, and genetic factors contributing to disease risk, manifestation and progression. Interestingly, the genetic predisposition in LOAD patients is considerable, with a heritability estimate of $60-80 \%$ [20]. The most common genetic risk factor is the apolipoprotein $\mathrm{E}$ (ApoE) gene (for review [21]). $A P O E$ is encoded by three common alleles: $\varepsilon 2, \varepsilon 3$, and $\varepsilon 4$. One copy of the $\varepsilon 4$ allele of APOE increases LOAD risk approximately 3-4 fold while two $\varepsilon 4$ copies increases LOAD risk by as much as 12 -fold [22, 23]. Interestingly, the $\varepsilon 2$ allele is associated with a decreased risk for LOAD and a later onset of disease. There are several mechanisms by which ApoE appears to play a role in AD pathogenesis. One important effect is that $A p o E$ isoforms influence $A \beta$ clearance, aggregation and metabolism [24-26]. In addition, recent studies suggest that ApoE modulates tau-mediated neurodegeneration in an isoform-specific manner [27].

For the last ten years, new whole-genome sequencing studies and genome wide association studies (GWAS) have made it possible to highlight several novel genetic factors linked with increased risk of LOAD. Several of these genetic risk factors encode proteins involved in microglial function and inflammation including TREM2, CD33, CR1, ABCA7 and SHIP1 (for reviews [28, 29]). In this review, we summarize the recent explosion of studies aiming to understand the role of microglia in LOAD. In particular, we focus on TREM2, a receptor of the innate immune system expressed in several types, as variants in the TREM2 gene have been found to increase LOAD-risk by 2-4 fold, similarly to what has been observed in patients with one copy of APOE $\varepsilon 4$. Many new models have been created to better understand the contributions of TREM2 in LOAD in light of this finding. Thus far, TREM2 studies further reiterate both the beneficial and detrimental effects of gliosis on neuronal health and degeneration, which are dependent on the context of the pathological insult and stage of disease. We further explore potential mechanisms by which TREM2 signaling may alter LOAD neuropathology. A better understanding of TREM2 and its impact in the disease is critical as TREM2 is currently being explored as a therapeutic target in LOAD.

\section{1) TREM2 structure and expression}

TREM2 belongs to a family of receptors referred to as the triggering receptors expressed on myeloid cells (TREM). Members of the TREM family are cell surface transmembrane glycoproteins with V-immunoglobulin extra-cellular domains and cytoplasmic tails [30]. The TREM2 gene is located on human chromosome $6 \mathrm{p} 21$ and encodes a 230-amino acid glycoprotein [31]. The TREM2 gene is expressed in a subgroup of myeloid cells including dendritic cells, granulocytes, and tissue-specific macrophages like osteoclasts, Kuppfer cells and alveolar macrophages [32-38]. In the brain, TREM2 is exclusively expressed by microglia [39-44]; however, there is some discordance regarding the level of its expression//translation [45-47] and whether or not TREM2 is present in all or only a subgroup of microglia [48] in mice and humans. Interestingly, the expression of TREM2 varies depending on the particular region of the central nervous system (CNS) [39, 49], with a higher expression in the hippocampus, the spinal cord and the white matter [41]. Its expression is modulated by inflammation, although inflammatory effects appear to be opposite in vitro and in vivo. Expression of anti-inflammatory molecules enhances TREM2 expression [50] while expression of pro-inflammatory molecules, such as TNF $\alpha$, IL1 $\beta$ or lipopolysaccharide (LPS), decrease TREM2 expression in vitro [32, 51, 52]. TREM2 expression is up regulated in pathological conditions such as Parkinson's disease (PD) [53], Amyotrophic lateral sclerosis (ALS) [54], stroke [55], traumatic brain injury [56] and $\mathrm{AD}$ [47, 57-59]. In $\mathrm{AD}$, increased expression of TREM2 has been confirmed in patients [47, 57-59] and in mouse models of amyloid and tau pathology [45, 6063 ] and seems to be associated with the recruitment of microglia to amyloid plaques [59, 64]. Interestingly, aging is also a factor that increases TREM2 expression in both mice and humans $[41,60]$. We could speculate that the acute inflammation mimicked by in vitro studies first induces a decrease of TREM2 expression while chronic inflammation observed in pathological conditions, such as $\mathrm{AD}$, results in an increase of TREM2 expression.

\section{2) TREM2 signaling and ligands}

TREM2 acts principally through the intracellular adaptor DAP12 (DNAX-activation protein 12, also known as TYROBP) through its short cytoplasmic tail [32, 65, 66]. Indeed, ligand-bound TREM2 is incapable of initiating intracellular signaling without DAP12 [43]. The association of TREM2 with DAP12 is coordinated by an electrostatic interaction between a conserved positively-charged lysine in TREM2 (aa186) and a negatively- charged aspartic acid residue in DAP12 (Figure 1) [66, 67]. TREM2 ligation generates tyrosine phosphorylation of DAP12 within its immunoreceptor tyrosine-based activation motifs (ITAMS) by Src family kinases (Figure 1). This phosphorylation creates a docking site for the $\mathrm{SH} 2$ domains of several molecules, initiating a signaling cascade and subsequent immune response [66]. The principal kinase recruited by the ITAM region of DAP12 is Syk, which activates downstream signaling components including phosphatidylinositol 3-kinase (PI3K), Akt, mitogen-activated protein kinases (MAPK) and increases intracellular calcium levels [43, 68-70]. TREM2 can also act through the DAP-10 adaptor, a relative of DAP-12, allowing the recruitment of PI3K [71]. 


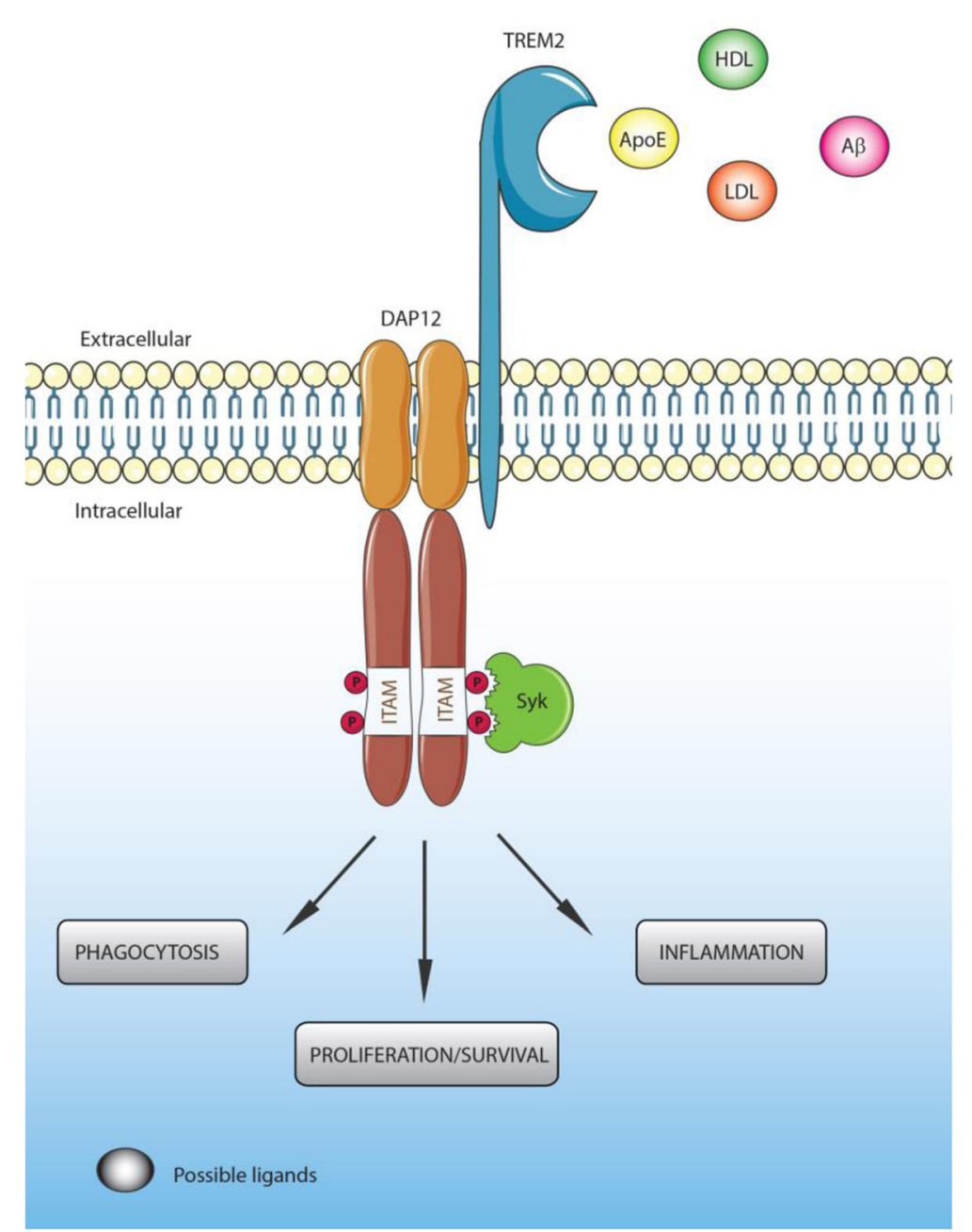

Fig. 1 TREM2 ligands, signaling and functions. Ligands binding to TREM2 induce the association of TREM2 to DAP12 through an electrostatic interaction between a conserved positively-charged lysine in TREM2 (aa186) and a negatively-charged aspartic acid residue in DAP12, generating tyrosine phosphorylation of DAP12 within its immunoreceptor tyrosine-based activation motifs (ITAMS) by Src family kinases

The exact identities of ligands that activate TREM2 remain uncertain. Early studies found that the TREM2 extracellular domain is able to bind microbial products such as LPS or lipoteichoic acids (LTA) [72]. Similarly to other TREM family members [73], lipids can bind and activate TREM2. Indeed, the putative structure of TREM2 contains a potential phospholipid binding site [73], which is confirmed by its crystal structure [74]. In addition, several studies demonstrated binding between TREM2 and lipids from cell membranes and lipoprotein complexes [73, 75, 76]. TREM2 has been reported to bind high-density lipoproteins (HDL), low-density lipoproteins (LDL) and several apolipoproteins such as ApoA1, ApoA2, ApoB and clusterin (ApoJ) [76-79]. However, one of the most well documented ligands of TREM2 is ApoE [76, 78, 79]. In vitro studies have demonstrated that lipidation of ApoE is not required for TREM2-ApoE binding [76, 78-80], although Yeh et al. suggested that ApoE lipidation enhanced this interaction [76].

It is interesting to note the interaction between TREM2, ApoE, and clusterin because all three are important genetic risk factors for LOAD, although binding between TREM2 and ApoE occurs with similar affinities between the three different $\mathrm{AD}$-associated ApoE isoforms $[64,78,79]$. In addition, a recent paper characterized $A \beta$ as a ligand of TREM2 [81]. The authors found that $A \beta$ was able to directly bind to TREM 2 and activate TREM2 signaling through DAP12 in vitro. Interestingly, an immunoprecipitation assay demonstrated a strong enhancement of TREM2-A $\beta$ interaction with oligomeric forms of $\mathrm{A} \beta$ compared to monomers [81]. While most ligands of TREM2 have been identified in vitro, a recent in vivo study by Ulrich et al. strongly argues that ApoE and TREM2 are in the same pathway [82]. Given that a lack of TREM2 expression impairs plaque-associated 
microgliosis in amyloid models, Ulrich et al. tested whether a lack of ApoE expression similarly affected the microglial response to amyloid plaques. They observed that mice lacking ApoE phenocopied mice lacking TREM2 in regards to the plaque-associated microglial response.

\section{3) TREM2 functions}

While the identities of TREM2 ligands remain uncertain, several functions of TREM2 have been well characterized in the last decade. TREM2 enhances the rate of phagocytosis. In vitro, loss of TREM2 in microglia and macrophages results in decreased phagocytosis of apoptotic neurons [43, 55, 78, 83], cellular debris [43] and bacteria or bacterial products [84-87]; increasing TREM2 expression improved phagocytosis rate of these substrates [43, 63, 85, 87, 88]. Moreover, TREM2 has been associated with $A \beta$ uptake in vitro, which will be discussed in a following section. In vivo, TREM2 KO mice had decreased levels of activated microglia and phagocytes in an experimental stroke model [55]. In a mouse model of multiple sclerosis, TREM2-transduced myeloid cells with lentivirus showed increased lysosomal and phagocytic activity [88]. It is noteworthy that lentiviruses and adeno-associated viruses (AAVs) have not been shown to transduce these cells in the brain efficiently. Regarding A $\beta$, microglia from 5XFAD mice without TREM2 internalized less methoxy- $\times 04$ (indicative of fibrillar $A \beta$ ) compared to microglia from 5XFAD mice with TREM2 [89]. In the same mouse model, A $\beta$ content was significantly reduced within CD68-immunolabeled microglial phagosomes when TREM2 was absent [90]. These findings in TREM2 deficient mice from multiple pathological models corroborate in vitro studies regarding TREM2's role in phagocytosis.

TREM2 also modulates inflammatory signaling. Most studies agree on the anti-inflammatory properties of TREM2. Indeed, Toll-like receptor (TLR) stimulation induced a higher release of pro-inflammatory cytokines, including TNF $\alpha$ and IL6, by bone marrow-derived macrophages lacking TREM2 [50] or DAP12 [91]. Anti-inflammatory effects of TREM2 after TLR stimulation have been confirmed in several cell lines [88, 92, 93]. In microglia, the knockdown of TREM2 signaling increased TNF $\alpha$ and NO synthase-2 transcription (NOS2), while overexpression of TREM2 decreased gene transcription of TNF $\alpha$, IL1 $\beta$ and NOS2 [43]. TREM2 also appears to signal through anti-inflammatory pathways in several pathological mouse models $[55,88,94]$. A recent study demonstrated that TREM2 mediates the switch from a homeostatic to a neurodegenerative microglia phenotype in APPPS1 and SOD1 (ALS mouse model) mice by inducing APOE signaling, a negative regulator of the homeostatic microglia transcription program [95]. Conversely, some studies reported that TREM2 promoted pro-inflammatory signaling $[32,96]$. Inspection of genes with the highest connectivity to TREM2 revealed both anti- and pro-inflammatory gene clusters in the brain [41]. These last findings strongly suggest a more complex action of TREM2 on inflammatory processes.

TREM2 has also been shown to modulate myeloid cell number, proliferation and survival. The ability of TREM2 to influence and, more specifically, to increase the number of myeloid cells is mostly described in disease contexts [55, 56, 84]. TREM2 enhances proliferation of several myeloid cell populations including microglia. In vitro, reduction of TREM2 in primary microglia cultures resulted in cell cycle arrest at the G1/S checkpoint [97]. Similarly, a decrease of microglial proliferation has been observed in different disease models when deficient for TREM2 [89, 98]. Finally, several studies suggested TREM 2 as a key factor for myeloid cell survival. Indeed, Zheng et al. reported decreased survival of primary microglia and BV2 microglial cells along with an alteration of the Wnt/ $\beta$-catenin activation pathway when TREM2 expression was reduced [97]. In accordance with these data, bone marrow derived macrophages and microglia deficient for TREM2 showed a lower survival rate after CSF1 starvation [75, 77, 99]. On the other hand, TREM2 activation improved dendritic cell survival through activation of the ERK pathway [32].

The functions of TREM2 previously described demonstrate the importance of TREM2 at the physiological and pathological level. Somehow, the loss of these functions in humans with homozygous loss-of-function mutations in TREM2 suffer from a severe form of dementia with bone cystic lesions known as Nasu-Hakola disease [100, 101]. How and why this particular disease occurs due to loss of TREM2 function is not yet clear. Several TREM2 variants in the human population are able to impair but not block functional TREM2 signaling and impact the onset and progression of $\mathrm{AD}$ as will be described in an upcoming section of this review. It is noteworthy that studies have also associated some TREM2 variants with other neurodegenerative diseases such as ALS [54, 102], Parkinson's disease [102, 103] and frontotemporal dementia [104-106], although these observations are still somewhat controversial [102, 104, 107].

\section{4) TREM2 variants and Alzheimer's disease}

Thanks to the recent development of whole genome sequencing and genome-wide association studies (GWAS), several genetic variants have been identified that increase the risk of developing LOAD. Among them, several rare variants in TREM2 have emerged that significantly increase LOAD risk by 2- to 4- fold, comparable to the increased risk associated with having one copy of APOE $\varepsilon 4$. The most common and most well studied TREM2 variant known to increase the risk of 
AD is rs75932628, a single nucleotide polymorphism encoding an arginine-to-histidine missense substitution at amino acid $47(\mathrm{R} 47 \mathrm{H})$. The $\mathrm{R} 47 \mathrm{H}$ variant was first identified as a risk factor for LOAD in 2013 by two independent studies on subjects of people of European or North American descent [108] and Icelandic subjects [109]. The association between the $\mathrm{R} 47 \mathrm{H}$ variant and LOAD in populations of European descent was thereafter corroborated by several studies [104, 107, 110118]. However, this risk variant has mostly present in European populations and the association of the $\mathrm{R} 47 \mathrm{H}$ mutant with increased LOAD risk does not seem to exist in Chinese and African-American populations [119123]. LOAD patients with the $\mathrm{R} 47 \mathrm{H}$ variant display an earlier onset of symptoms $[107,109]$ and faster cognitive decline [124] compared to non-carriers, although these results are not always consistent between studies [107, 117, 125]. Interestingly, in a European cohort, the R47H variant of TREM2 increased the level of total tau protein in the CSF without affecting A $\beta 42$ [102]. These data suggest a link between $\mathrm{AD}$-associated pathologies and the R47H TREM2 variant. Other TREM2 variants have also been suggested as risk factors for developing LOAD, including R62H (rs143332484), D87N (rs142232675), T96K (rs2234353), L211P (rs2234256) and R136Q (rs149622783) [77, 108, 110, 112, 115, 126].

Identification of these new TREM2 variants as LOAD genetic risk factors has prompted many scientists to study their impact on TREM2 functions. Most of the studies have determined that AD-associated TREM2 variants do not affect folding, expression, stability or structure of TREM2 in AD brains [58, 77, 85]. However, Kober et al. do suggest that the $\mathrm{R} 47 \mathrm{H}$ mutation induces a small, but measurable, conformational change in TREM2, and that the R47H and R62H TREM2 variants exhibited slightly decreased stability compared to the common variant [74]. AD-associated variants do appear to affect the affinity of TREM2 for its ligands. Indeed, binding assays revealed that $\mathrm{R} 47 \mathrm{H}, \mathrm{R} 62 \mathrm{H}$ and $\mathrm{D} 87 \mathrm{~N}$ variants exhibit impaired interactions with lipoprotein ligands including ApoE, LDL and clusterin in vitro [74, 76, 78, 79]. Conversely, Kober et al. reported that the T96K variant increased TREM2 affinity to cell-surface ligands, while confirming reduced binding of cell-surface ligands by $\mathrm{R} 47 \mathrm{H}$ [74]. AD-associated variants disturb TREM2 signaling in a pattern similar to that observed for affinity: $\mathrm{R} 47 \mathrm{H}$ and $\mathrm{R} 62 \mathrm{H}$ negatively affect TREM2 activity in vitro, while T96K activity was enhanced compared to the common variant of TREM2 [75, 77]. However, this correlation between affinity and signaling strength does not apply to the D87N variant, which induces a decrease in ligand binding but an increase in TREM2 signaling [77]. This highlights the need for better understanding of the complex action of TREM2. Finally, R47H and R62H variants have been shown to slightly alter phagocytic functions of TREM2 in vitro [76, 85]. Moreover, R47H missense mutation impairs TREM2 maturation and alters shedding by $\alpha$-secretase [85]. Finally, Yeh et al. demonstrated a decrease of A $\beta$-lipoprotein complex uptake by blood monocyte-derived macrophages from patients heterozygous for the R62H variant [76].

Over the last 5 years, considerable efforts have been made to better understand how different TREM2 variants can affect the risk of $\mathrm{AD}$ in vitro. These studies have found that these variants result in a decrease of TREM2 functions. It is now essential to confirm and further explore these data in vivo using animal models of $\mathrm{AD}$ and in patients in order to elucidate the precise mechanisms linking the TREM2 variants to $A D$.

\section{5) TREM2 and amyloid pathology in AD TREM2 and amyloid burden}

A large majority of in vivo studies aimed at understanding the link between TREM2 and AD have focused on amyloid pathology. Most of these studies used different mouse models of amyloid deposition with total or partial deletions of TREM2. Unfortunately, while in vitro studies suggested that TREM2 is strongly involved in $A \beta 40$ and $A \beta 42$ uptake by microglia $[63,85,127]$, experiments performed in vivo found more inconsistent results regarding TREM2 function in $A \beta$ uptake by microglia. The APPPS1-21 [128] and 5xFAD [129] mouse models have mainly been used to assess the effect of TREM2 deficiency or haplo-insufficiency on $A \beta$ accumulation. In APPPS1-21 mice, TREM2 haplo-insufficiency did not affect $A \beta$ accumulation in the cortex [130]. A total deletion of TREM2 in the APPPS1-21 mouse model resulted in a decreased $A \beta$ burden in the cortex of 2-month-old mice but in a higher $A \beta$ accumulation in the cortex of 8-month-old mice [131]. In 5xFAD mice, Wang et al. reported that TREM2 deletion increased $A \beta$ pathology (insoluble $A \beta 42$ and $A \beta$ load) in the hippocampus but not in the cortex of 8.5-month-old mice, with an intermediate phenotype in TREM2-haplo-insufficient mice [75, 89]. These data suggest an age-dependent or $A \beta$ burdendependent effect of TREM 2 on $A \beta$ deposition. Therefore, TREM 2 could result in greater $A \beta$ deposition in the early stages of the disease and then result in less $A \beta$ deposition in later stages. A time course analysis of $A \beta$ burden in these two TREM2-deficient models will be necessary to confirm this hypothesis. Moreover, the use of a less aggressive model of $A \beta$ deposition will be useful in order to finely dissect the effect of TREM2 on $A \beta$ accumulation. $[45,75,130][132,133]$

\section{TREM2 and microglial function}

Whereas the effect of TREM2 on A $\beta$ deposition remains unclear, studies have unanimously reported decreased 
microglial activation in APPPS1-21 and 5xFAD mice deficient or haplo-insufficient for TREM2, resulting in a subsequent reduction of plaque-associated microglia [45, $75,130]$. Importantly, microglia also failed to cluster around plaques in APPPS1-21 mice haplo-insufficient or deficient for DAP12 [90], confirming the need for TREM2 signaling to activate microglia and recruit them to the plaques. The inability of microglia to cluster around plaques without TREM2 was associated with defects in plaque compaction, microglia proliferation, and increased levels of dystrophic neurons [75, 89, 90]. Moreover, microglia that lacked TREM2 exhibited strong metabolic defects, including low ATP levels and elevated stress markers such as autophagic vesicles. This was caused by defective mammalian Target Of Rapamycin (mTOR) signaling [134]. These results suggest that TREM2 provides trophic support for microglia in stressful conditions. In cases of prolonged stress or activation, as seen in $\mathrm{AD}$, a defective TREM2 could then alter microglial functions and survival through deficient mTOR signaling, resulting in exacerbation of $\mathrm{AD}$ neuropathologies.

Recently, Lee at al. used a BAC transgene to induce human TREM2 (hTREM2) expression in 5xFAD mice [135]. Compared to $5 \times$ FAD mice deficient or haplo-insufficient for TREM2 [75, 89, 136], 5xFAD mice expressing human TREM2 exhibited reduced insoluble and soluble A $\beta 42$, diminished plaque area, more compact plaques and fewer dystrophic neurites in the cortex [135]. The authors demonstrated that expression of hTREM2 resulted in a reprogrammed microglial gene expression signature. Interestingly, human TREM2 expression was associated with the upregulation of some "disease-associated microglial genes" involved in microglial function, such as phagocytosis. Following this observation, the authors confirmed that phagocytic microglia markers such as CD68 and Lgasl3 in were increased in 5xFAD mice expressing hTREM2. This study confirmed several TREM2 functions previously described in TREM2-deletion mouse models and suggested that reprogrammed microglial gene expression is a key function of TREM2 in the A $\beta$-deposition models.

Recent findings by Zhao et al. revealed that TREM2 is an $A \beta$ receptor that mediates microglial functions [81, 137]. As previously mentioned, the authors demonstrated TREM2-A $\beta$ interactions using co-immunoprecipitation, cell-free, solid-phase and cell-based binding assay; this interaction was stronger with oligomeric forms of $A \beta$ compared to monomers [81, 137]. A $\beta /$ TREM2 binding activated TREM2 signaling and induced microglia depolarization and $A \beta$ degradation. Moreover, microglia without TREM2 displayed defective clearance of $A \beta$, with longer internalization of $A \beta$ and an impaired $A \beta$-induced pro-inflammatory response. In vivo, Zhao et al. described alterations in $A \beta$ degradation as well as microglial proliferation and apoptosis in A $\beta$-injected TREM2 deficient mice [81]. Altogether, these data suggest that oligomeric forms of $A \beta$ may activate TREM2 signaling through direct binding resulting in a pro-inflammatory response, $A \beta$ degradation and microglial proliferation. Moreover, these results could explain why TREM2 is necessary for the recruitment of microglia to plaques.

Importantly, Zhao et al. also reported that the $\mathrm{R} 47 \mathrm{H}$ and $\mathrm{R} 62 \mathrm{H}$ hTREM2 variants compromised the interaction between oligomeric $A \beta$ and TREM2-Fc [81]. We can therefore speculate that the mechanism by which TREM2 variants increase the risk of LOAD is by altering TREM2's A $\beta$-receptor functions. However, these in vitro data have not yet been confirmed by in vivo studies [82]. Indeed, Ulrich et al. demonstrated that a lack of ApoE expression affects microglial recruitment to amyloid plaques, which is phenotypically similar to what has been observed in mice lacking TREM2 expression. These in vivo observations suggest that if TREM2 is able to bind $\mathrm{A} \beta$, as suggested by in vitro studies, it does not seem able to bind $A \beta$ in plaques in the absence of ApoE to result in microglial recruitment and reduce neuritic dystrophy. Further studies characterizing AD-associated TREM2 variants in the context of amyloid pathology are thus needed to confirm this hypothesis and better understand how TREM2 variants promote LOAD.

\section{The biologic impacts of hTREM2 variants}

Two studies aimed at clarifying the impact of human TREM2 variants in LOAD have been published to date. In the first of these studies, Song et al. generated transgenic mice expressing the common variant or $\mathrm{R} 47 \mathrm{H}$ variant of human TREM2 via BAC transgenes in a TREM2-deficient 5xFAD mouse background [132]. They reported that only the common variant of TREM2 was able to restore microgliosis and microglial activation induced by amyloid pathology in this model, while mice expressing the $\mathrm{R} 47 \mathrm{H}$ variant displayed impaired microglial activation and recruitment to plaques. These results are similar to the observations made in TREM2-deficient 5xFAD mice [132]. Moreover, the authors found that soluble TREM2 released from microglia membranes is found in plaques and neurons of 5xFAD mice with the common variant of TREM2, but not in $5 x F A D$ mice with the $\mathrm{R} 47 \mathrm{H}$ variant of TREM2. Importantly, soluble TREM2 (corresponding to the TREM2 ectodomain previously described) was identified as a receptor for oligomeric A $\beta[81,137]$. This suggests a possible direct binding between soluble TREM2 and plaques in the brains of 5xFAD mice expressing the common variant of TREM2 but not in the brains of mice expressing the $\mathrm{R} 47 \mathrm{H}$ variant $[81,137]$. However, the impact of this possible interaction between soluble TREM2 and oligomeric $\mathrm{A} \beta$ on $\mathrm{AD}$ remains to be further explored. 
In a subsequent study, Cheng-Hathaway et al. used APPPS1-21 mice in which CRISPR/Cas9 was used to knock in the $\mathrm{R} 47 \mathrm{H}$ TREM2 variant into the endogenous mouse TREM2 gene [133]. APPPS1-21 mice heterozygous for the R47H TREM2 variant exhibited reduced association of microglia to plaques, lowered $A \beta$-induced microglial activation and proliferation, more diffuse amyloid plaques and increased plaque-associated neuritic dystrophy. These results are comparable to observations made in both A $\beta$-deposition and APPPS1-21 mouse models that are haplo-insufficient or deficient for TREM2 [45, 75, 89, 130, 131]. Surprisingly, a strong reduction of TREM2 mRNA was observed in APPPS1-21 mice heterozygous for the R47H TREM2 variant, which differs from a human study that reported no change in TREM2 expression in the brain of AD patients heterozygous for the $\mathrm{R} 47 \mathrm{H}$ variant [58]. Interestingly, a similar decrease of plaque-associated microglia, the presence of less compact plaques and higher neuritic dystrophy around plaques has also been observed in $\mathrm{AD}$ patients expressing the $\mathrm{R} 47 \mathrm{H}$ variant of TREM2 compared to those patients expressing the common TREM2 variant, confirming the partial loss-of-function caused by the $\mathrm{R} 47 \mathrm{H}$ variant [136]. Taken together, these in vivo studies confirmed the suspected partial TREM2 loss-of-function phenotype of the LOAD-associated $\mathrm{R} 47 \mathrm{H}$ variant. Importantly, a new study by Xiang et al. has explored the cause of TREM2 RNA reduction in this CRISP/Cas9 model [138]. They reported that the $\mathrm{R} 47 \mathrm{H}$ variant activated a cryptic splice site, which introduced a premature stop codon in mice but not in human TREM2, resulting in haplo-insufficiency of the Cheng-Hathaway et al. model. These data strongly suggest that results obtained with this model should be interpreted carefully and may not be directly translatable to humans.

To conclude, these studies in mouse models of amyloid deposition indicate a critical function for TREM2 in the clustering of microglia around plaques, plaque compaction, and microglia proliferation and activation, which may be disturbed by some rare TREM2 variants. TREM2 signaling appears to both positively and negatively affect amyloid pathology depending on disease progression. AD-associated TREM2 variants may induce partial loss-of-function phenotypes, resulting in an inability of microglia to cluster around plaques. These findings advance our understanding of TREM2 involvement in the response of microglia to $A \beta$ aggregation and its consequences and strongly encourage targeting and enhancing TREM2 expression and/or signaling early in $\mathrm{AD}$ pathogenesis to reduce $\mathrm{A} \beta$-induced brain injury associated with TREM2 defects in AD. However, the $A \beta$ deposition phase of $\mathrm{AD}$ occurs predominantly prior to symptom onset in humans. Questions still remain regarding the role of TREM2 and its different variants in later stages of $\mathrm{AD}$, in particular in tau pathology and tau seeding.

\section{6) TREM2 and tau pathology in AD First clues linking TREM2 to tau pathology}

Numerous findings in the literature suggest a link between tau pathology and TREM2 in LOAD. Indeed, in the cerebrospinal fluid (CSF) of AD patients, soluble TREM2 has been shown to correlate with total and phosphorylated tau (Thr181) levels, but not with levels of A $\beta 42$ [139]. Moreover, AD patients harboring the $\mathrm{R} 47 \mathrm{H}$ variant of TREM2 display higher levels of both total tau and phosphorylated tau (Thr181) in CSF compared to non-carriers, without any change in A $\beta 42$ levels [102, 140]. Importantly, levels of phosphorylated tau in the CSF correlate with tau pathology burden in the brain (both in terms of neurofibrillary tangles and hyperphosphorylated tau loading) [141] and with neuronal loss and cognitive decline in AD patients [141-143]. Importantly, a study reported increased tau hyperphosphorylation and axonal dystrophy around amyloid plaques in humans harboring the R47H variant of TREM2 [90]. A study also found a positive correlation between TREM2 mRNA levels and tau burden in a cohort of 20 AD patients and 12 controls [57]. Additionally, microglia have been strongly characterized as key players in tau pathology and propagation [144-147]. Indeed, in a mouse model of tau propagation using an injection of AAV2/ 6-SYN1 promoter driving the expression of human P301L tau 1-441 mutant into the entorhinal cortex, Asai et al. report that depleting microglia dramatically suppressed the propagation of Tau [147]. Moreover, Luo et al. demonstrated that microglia degrade human tau species released from AD brains and eliminate NFTs from PS19 mice, a mouse model of tauopathy harboring the P301S human tau mutation [145]. In hTau mice, another tauopathy mouse model, microglial activation has been shown to correlate with a deficit in spatial memory and the spread of tau pathology [146]. While preliminary, these data suggest a role for microglia in tau pathology and tau propagation in $\mathrm{AD}$, which can be affected by AD-associated TREM2 variants. However, only a few studies have investigated the link between tau and TREM2 compared to the extensive number of studies aimed at understanding the link between TREM2 and A $\beta$.

Some studies have assessed tau phosphorylation in A $\beta$-deposition mouse models deficient for TREM2. However, the results reported in these studies are inconsistent, and demonstrate either an increase [89] or decrease [45] of phosphorylated tau in mice deficient for TREM2. This may be because of differences in the mouse models used (5xFAD vs. APPPS1). A recent study also suggested that overexpression of TREM2 through 
ICV injection of AAV encoding the murine TREM2 gene was able to decrease surgery-induced tau hyperphosphorylation in APPswe/PS1dE9 mice [148]. However, it is important to note that robust microglial transduction has not been reported in vitro using commonly used AAVs (1-9).

\section{TREM2 functions in models of pure tau pathology}

Although investigating the effects of TREM2 on tau pathology in the context of amyloid pathology is essential to better understand AD, studies of the direct link between TREM 2 and tau pathology are very rare. Only 5 studies of TREM2 in pure tau pathology exist today in the literature. Two of these studies have been done by Jiang et al. in PS19 mice, a model of tauopathy harboring the P301S mutation $[149,150]$. In the first study, the authors suggested that the silencing of brain TREM2 via injection of a lentivirus containing TREM2 shRNA was able to exacerbate tau phosphorylation through neuroinflammation-induced hyperactivation of tau kinases [150]. Moreover, data presented in this study suggests an exacerbation of neurodegeneration and higher spatial learning deficits in PS19 mice expressing TREM2 shRNA compared to mice not deficient in TREM2. In the second study, they induced TREM2 overexpression in microglia of PS19 mice with a lentivirus containing TREM2 cDNA. In agreement with their first study, the authors observed that overexpression of TREM2 in microglia reduced neurodegeneration, spatial cognitive impairments and tau hyperphosphorylation through the suppression of neuroinflammation-induced hyperactivation of tau kinases [149]. Although both articles have relevant hypotheses and provide encouraging results, a significant technical issue exists in these studies. Clear evidence that the lentiviruses utilized were able to infect and alter TREM2 levels in microglia is lacking. In the first study, the authors were able to confirm an increase in TREM2 mRNA levels specifically in microglia during disease progression in PS19 mice [150]. However, they did not use the same technique to assess the efficiency of their lentiviruses and only assessed TREM2 mRNA levels in whole cortex and hippocampus (not only in microglia) $[149,150]$. To confirm that the lentiviruses altered TREM2 expression in microglia, they performed TREM2 immunofluorescence staining in mouse brains but the authors mention possible non-specific binding with the antibodies utilized [149, 150]. To summarize, due to the lack of important controls, results obtained in these studies are not sufficient to confidently understand how TREM2 affects tau pathology.

Three recent studies tackled this problem by crossing TREM2 knockout mice with two different murine models of tauopathies [151-153]. In the first study, Leyns et al. reported a decrease in neurodegeneration as well as attenuated microgliosis and astrogliosis in the brains of PS19 mice deficient for TREM2 [152]. Interestingly, no differences were observed for tau phosphorylation and insolubility in PS19 mice with or without TREM2. These unexpected results suggest that TREM2 promotes neuroinflammation and neurodegeneration in the context of tauopathy. In a second study, Sayed et al. [153] found that TREM2 haplo-insufficiency, but not complete loss of TREM2, increased tau pathology. Further, whereas complete TREM2 deficiency protected against tau-mediated microglial activation and atrophy as seen by Leyns et al. [152], TREM2 haplo-insufficiency elevated expression of proinflammatory markers and exacerbated atrophy at a late stage of disease. Taken together, these 2 studies suggest that partial or normal TREM2 function contributes to tauopathy as well as tau-mediated damage and that complete loss of function also decreases tau-mediated brain injury. In a third study, Bemiller et al. crossed TREM2 knockout mice with hTau mice [151], which is a mouse model of tauopathy expressing all human Tau isoforms in a murine tau knockout background [154]. Bemiller at al. confirmed the decrease of microgliosis in TREM2-deficient hTau mice, as previously seen in TREM2-deficient PS19 mice [151-153]. However, unlike studies on PS19 mice, complete deletion of TREM2 in hTau mice exacerbated tau phosphorylation and insolubility. The authors suggest that these changes are driven by the activation of stress-related tau protein kinases in TREM2-deficient hTau mice. Neurodegeneration was not evaluated in this study. These pure tauopathy mouse models suggest a complex relationship between TREM2 and Tau pathology, which requires further research. hTau and PS19 mice are independent mouse models and develop distinctive pathologies, which may explain differences between these models. Given the results of the current studies, it will be important to understand the effects of human TREM2 and human TREM2 variants in both pure tauopathy models that develop tau pathology and neurodegeneration as well as the effects of TREM2 in models that develop both $A \beta$ and tau pathology.

Recently, an interesting study evaluated molecular and pathological interactions between A $\beta 42$, tau, TREM2, and DAP12 in Drosophila models [155]. They created flies that expressed human tau in photoreceptor neurons and either WT or R47H TREM2/DAP12 complexes in glia cells simultaneously. Results obtained in this new model demonstrated that glial expression of both TREM $2{ }^{\mathrm{WT}} / \mathrm{DAP} 12$ and TREM $2^{\mathrm{R} 47 \mathrm{H}} / \mathrm{TDAP} 12$ complexes significantly exacerbated tau-mediated neurodegeneration without affecting tau phosphorylation and insolubility, in agreement with the Leyns et al. and Sayed et al. studies in TREM2 deficient PS19 mice [152, 153]. On the other hand, a recent in vitro study using a microglia/ 
neuron co-culture model, reported that depletion of TREM2 exacerbated tau phosphorylation via an increase in the microglial inflammatory response [156]. These results are in agreement with the findings reported by Bemiller et al.

Taken together, studies assessing the link between tau pathology and TREM2 suggest a biphasic effect of TREM2 loss-of-function, similar to what has been seen for amyloid pathology. In the early stages of the disease, dysfunctional TREM2 can promote tau pathology (both hyperphosphorylation and aggregation), while the complete loss of TREM2 function in advanced stages of the disease seems to protect from neurodegeneration.

\section{7) TREM2 and ApoE: a close partnership in AD pathogenesis?}

Beyond the direct contribution of TREM2 and its AD-related variants on the two histopathological markers of LOAD (i.e. amyloid plaques and NFTs), a new hypothesis has started to emerge suggesting a collaboration between ApoE and TREM2 in LOAD pathogenesis. This hypothesis is based on a combination of several observations. First, APOE and TREM2 are, to date, the two largest genetic risk factors that influence the development of LOAD [157]. Second, ApoE is now well-characterized as a TREM2 ligand in vitro, which may stimulate TREM2 functions [76, 78-80]. Interestingly, binding between TREM2 and ApoE occurs to a similar extent between the three different ApoE isoforms [64, 78-80]. Another study showed higher TREM2 expression in patient-derived mononuclear blood cells from ApoE ع4-carriers with mild cognitive impairment and AD compared to non-carriers [158]. Moreover, decrease of TREM2 in microglia has been reported in mice expressing ApoE ع4 [159]. Recently, Murray et al. suggested that ApoE $\varepsilon 4$ is required in TREM2 $\mathrm{R} 47 \mathrm{H}$ variant-carriers for $\mathrm{AD}$ to develop, although larger cohorts and statistical analyses are needed to support this hypothesis [160].

At the microglial level, quantification of ApoE transcripts isolated from both WT and TREM2-deleted mice using fluorescence-activated cell sorting and nanostring technology revealed a downregulation of ApoE expression in TREM2-deleted mice [161]. In PS19 mice, Leyns et al. reported the accumulation of ApoE-positive puncta specifically in microglia [152]. Deletion of TREM2 in this model strongly lowered the number of microglia containing ApoE puncta, and decreased the gene expression of ApoE in the cortex. Moreover, the same reduction in neurodegeneration induced by tau pathology in PS19 mice has been reported when mice lack TREM2 [152] or ApoE [27]. This suggests a strong contribution of TREM2 and ApoE in neurodegeneration in this model. Recent findings by Ulrich et al. also suggest that
ApoE and TREM2 are in the same pathway [82]. Indeed, amyloid mice lacking ApoE phenocopied mice lacking TREM2 in regards to the plaque-associated microglial response. Taken together, these data suggest a possible relationship between TREM2 and ApoE in AD, although the exact nature of this alliance and its consequences in $\mathrm{AD}$ remained, until recently, poorly understood.

A new study has shed light on the function of the TREM2/ApoE connection in neurodegenerative diseases including $\mathrm{AD}$ [95]. In this study by Kraesmann et al., a specific molecular signature has was identified in microglia from several mouse models of neurodegenerative diseases, including $\mathrm{AD}$ [95]. This neurodegeneration-associated phenotype acquired by microglia $(\mathrm{MGnD})$ is characterized by transcriptional changes, including decreased expression of 68 homeostatic genes, and increased expression of 28 inflammatory genes. Because the downregulation of ApoE observed in microglia during development is correlated with a homeostatic profile, the authors next aimed to assess the role of ApoE in the induction of $\mathrm{MGnD}$ in microglia [162]. To this end, they performed transcriptomic analysis in APOE-deleted microglia and observed that ApoE regulates the MGnD transcriptional program. Moreover, because TREM2 binds ApoE, the authors then evaluated if the ApoE-induced switch from a homeostatic profile to MGnD in microglia was TREM2-dependent. Deletion of TREM2 in APPPS1-21 mice suppressed the MGnD profile, locking microglia in the homeostatic phenotype. This suggests that the TREM2/ApoE pathway is able to drive the switch from homeostatic microglia to neurodegenerative microglia, MGnD being less effective at preventing neuronal loss. This novel study provides many answers regarding the relationship between TREM2 and ApoE in neurodegenerative diseases. However, it is still not clear whether ApoE or TREM2 are upstream or downstream of each other in this pathway.

Altogether, these data indicate a strong collaboration between TREM2 and ApoE in several neuropathological hallmarks of LOAD. However, these discoveries raise new questions regarding the exact mechanism underlying this collaboration and the origin of ApoE involved in this partnership, which require further investigation. Moreover, these data reveal that a more exhaustive study of ApoE specifically in microglia is now necessary to better understand the link between $\mathrm{AD}$ and microglia.

\section{8) TREM2: a brain teaser for therapeutic strategy in AD}

Despite more than a century of research on AD, there is currently no treatment to prevent or cure the disease. Current treatments aiming to slow the progression of the disease target neurotransmission pathways altered in AD. The U.S. Food and Drug Administration has approved two types of medications that aim to slow down 
Table 1 Summary of the major findings on TREM2 in AD context

\begin{tabular}{|c|c|c|c|}
\hline AD context & Major TREM2-AD related findings & Source & Citations \\
\hline Risk factors & $\begin{array}{l}\text { Rare variants in TREM2 increase LOAD risk } \\
\text { by } 2 \text { - to } 4 \text { - fold }\end{array}$ & AD patients & {$[104,107-118]$} \\
\hline \multirow[t]{2}{*}{ Amyloid pathology } & $\begin{array}{l}\text { Loss of functional TREM2 decreases microgliosis } \\
\text { around plaques }\end{array}$ & $\begin{array}{l}\text { 5xFAD mice } \\
\text { APPPS1-21 mice }\end{array}$ & {$[45,75,130,132,133]$} \\
\hline & $\begin{array}{l}+ \text { Loss of functional TREM2 decreases plaque } \\
\text { compaction }\end{array}$ & $\begin{array}{l}\text { 5xFAD mice } \\
\text { APPPS1-21 mice }\end{array}$ & {$[75,89,90,133]$} \\
\hline \multirow[t]{2}{*}{ Tau pathology } & $\begin{array}{l}* \text { TREM2 deletion decreases tau-mediated } \\
\text { neurodegeneration }\end{array}$ & PS19 mice & {$[152,153]$} \\
\hline & $\begin{array}{l}\text { - TREM2 deletion (1) or haploinsuficiency (2) } \\
\text { increase tau pathology }\end{array}$ & $\begin{array}{l}\text { hTau mice (1) } \\
\text { PS19 mice (2) }\end{array}$ & $\begin{array}{l}{[151](1)} \\
{[153](2)}\end{array}$ \\
\hline \multirow[t]{2}{*}{ ApoE } & * ApoE is a TREM2 ligand & in vitro & {$[76,78,79]$} \\
\hline & $\begin{array}{l}\text { ApoE-induced switch from homeostatic to } \\
\text { neurodegenerative microglia is TREM2-dependent }\end{array}$ & APPPS1-21 mice & [95] \\
\hline
\end{tabular}

AD: cholinesterase inhibitors (Aricept, Exelon, Razadyne) and the NMDA receptor antagonist memantine (Namenda). However, the efficiency of these drugs has often been questioned (for review [163]). Although a considerable effort has been made to find new treatments, none have been met with any success yet in clinical trials.

While a great interest in TREM2 as a therapeutic target in $\mathrm{AD}$ is emerging, many impediments make its use potentially challenging. First, TREM2 risk variants are found in less than one percent of the population. In comparison, ApoE $\varepsilon 4$-carriers represent $20 \%$ of the population [113, 164]. Although several studies suggest that, in certain conditions, targeting TREM2 could decrease AD-related pathologies as previously described, it is still unknown whether a potential TREM2-targeting treatment will be effective in non-carrier AD patients, which represent the majority of cases. Moreover, it remains to be determined whether a therapeutic strategy targeting TREM2 should activate or inhibit it. Indeed, as

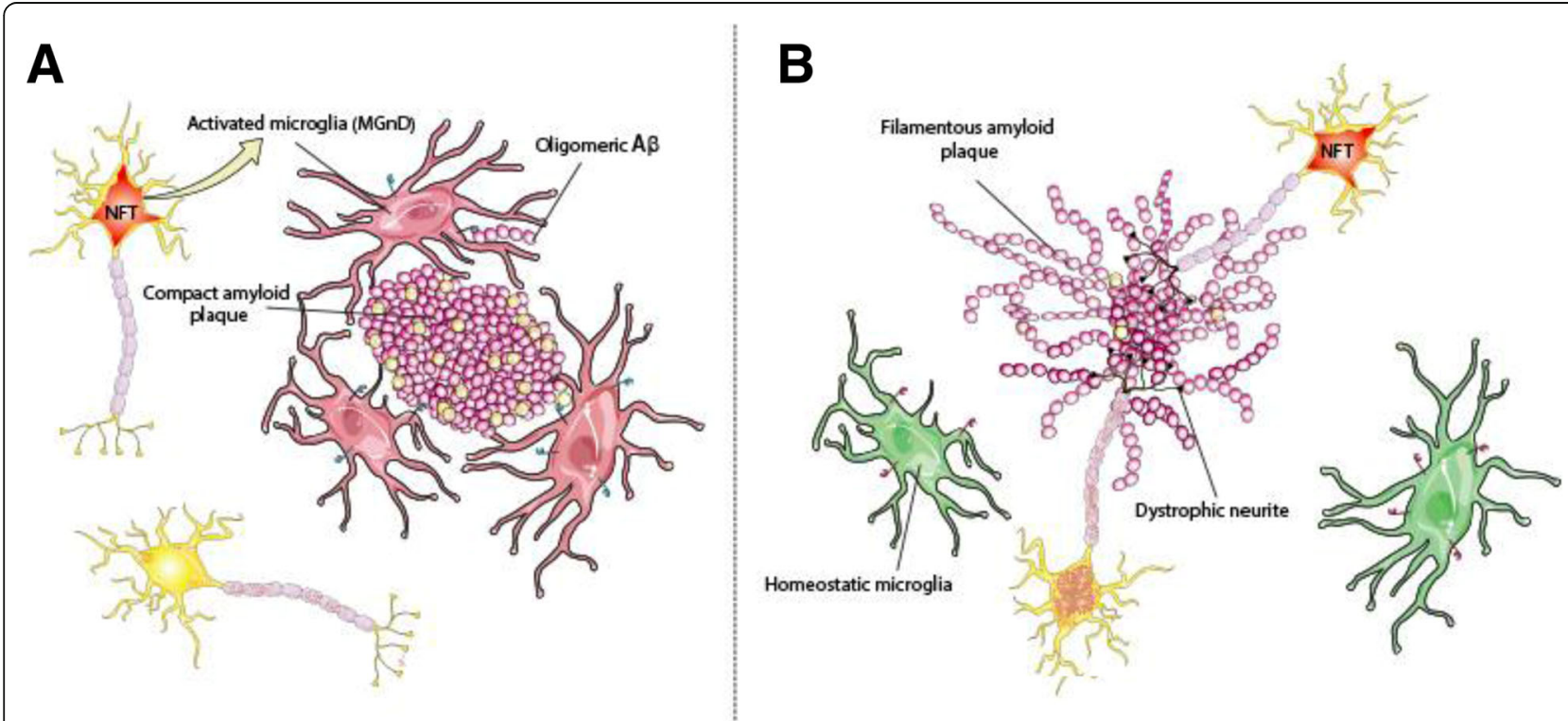

(AB ADOE) C TREM2 F $C_{\text {AD- assodated TREM2 variants }}$ Phosphorylated tau proteins

Fig. 2 Schematic summary of the role of TREM2 and its variants in AD. a. Functional TREM2 has been suggested to allow microglia activation (by amyloid and NFTs for example), promote microglia clustering around plaques, amyloid uptake (early stage of the disease) and plaque compaction through binding to plaque-associated ApoE or directly to oligomeric A 3 . b. AD-associated TREM2 variants resulting in TREM2 partial lossof-function abolished microglia clustering around plaque and phagocytic activity. These changes could be caused by a blockage of microglia in homeostatic stages because of less plaque-associated ApoE or other reasons. The consequences are filamentous plaques associate with increased dystrophic neurites and a possible increase of tau pathology (in early stages) 
previously discussed, TREM2 can be either beneficial or pathological in $\mathrm{AD}$ depending on the disease models used, the context of the pathological insult, and the stages of pathology. To date, the best strategy seems to involve stimulating TREM2 signaling in the early stages of the disease, when amyloid deposition starts and before tau pathology and neuronal loss occurs. However, because of the dual role of TREM2 in AD, this hypothesis must be carefully tested to avoid worsening disease pathology. A similar strategy would be to stimulate TREM2 even before amyloid deposits form in the brain. Indeed, TREM2 deficiency prevents the transition of microglia to the MGnD phenotype, which prevents the beneficial effects of microglia on amyloid pathology [165]. Stimulating the microglial transition from homeostatic states to $\mathrm{MGnD}$ prior to amyloid accumulation may therefore delay the evolution of AD. Conversely, the observation that deletion of TREM2 in APPPS1-21 mice decreased the $A \beta$ burden in 2-months-old animals but resulted in higher $A \beta$ accumulation in the cortex of 8-months-old animals [131] suggests that MGnD could be beneficial in the later stages of amyloid pathology. This example highlights the complexity of targeting TREM2.

While the timing of when to stimulate TREM2 in order to treat $\mathrm{AD}$ pathology needs to be resolved, the question of how to target TREM2 also remains unaddressed. Immunotherapy using antibodies to stimulate TREM2 signaling are being developed by a number of groups. TREM2-activating antibodies have been tested in vitro and have been shown to induce activation of calcium and ERK signaling in human dendritic cells [32]. Such a strategy requires particular thoughtfulness because antibodies could alter binding of TREM2 ligands [75]. Modulating TREM2 expression or protein levels is another strategy of interest. Indeed, overexpression of TREM2 in vitro decreases inflammation and promotes phagocytosis [43]. In vivo, lentiviral approaches aiming to increase TREM2 expression in the brains of mice attenuated both cognitive and neuropathologic alterations [63]. However, it is important to note that lentiviral strategies cannot be used in humans because of the high risk of inducing oncogenic transformation.

Regardless of the strategy chosen to modulate TREM2 in $\mathrm{AD}$, it is important to remember that microglia are not the only cells that express TREM2. Targeting of this receptor outside the brain will need to be assessed to make sure there are not unwanted side effects. Further, even in the brain, microglial functions are not limited to inflammatory responses (for review [166]) and modulating TREM2 signaling could induce several deleterious side effects that will have to be assessed. It seems obvious that the targeting of TREM2 in AD is a promising avenue to explore. However, there are clearly several obstacles that will need to be addressed before moving forward with such a strategy. The growing interest in TREM2, especially in the context of AD, may hopefully provide a better characterization of its roles and thus help to find a way around the possible barriers to its therapeutic targeting.

\section{Conclusion}

Despite a continually growing number of cases, $A D$ is still under-characterized. In addition to the role of amyloid pathology, it is now clear that the pathogenesis of $\mathrm{AD}$ involves many alterations in the brain that interact synergistically, ultimately resulting in neuronal death. Beyond tau and amyloid pathologies, growing evidence suggests that neuroinflammation plays a crucial role in AD. Recent genetic studies (GWAS and whole genome sequencing) have confirmed this by identifying numerous genetic risk factors for $\mathrm{AD}$ associated with the immune system. Within these new genetic risk factors, a special interest has been directed at TREM2 in the last 5 years. Together, the data presented in this review strongly suggest an important role of TREM2 in AD at the level of amyloid and tau pathologies and inflammation, alone or in collaboration with other molecules such as ApoE (Table 1). Figure 2 illustrates current thinking and hypotheses regarding the role of TREM2 and its rare $\mathrm{AD}$-associated variants in $\mathrm{AD}$ pathogenesis. Studies on TREM2 in the context of AD highlight its complexity. Indeed, in vivo studies suggest that TREM2 is injurious in the early stages of the disease and then becomes beneficial in the later stages. Finally, both $\mathrm{ApoE}$ and oligomeric forms of $A \beta$ are able to bind and activate TREM2 making the elucidating of the TREM2 mechanism of action in AD difficult.

Therefore, there are many outstanding questions that require further investigation. Most of the previously performed studies evaluated how TREM2 influences AD pathogenesis through partial or total deletion of TREM2. However, AD-related risk factors have also been associated with partial loss-of-function of TREM2. Consequently, further studies are needed to understand how these specific human risk variants affect AD. Furthermore, it is also necessary to understand the dual role of TREM2 in AD, which can reflect the often-reported dual role of neuroinflammation in this disease. In the same way, how TREM2 variants exactly alter AD remains unclear. Is it because of altered phagocytosis resulting in the accumulation of amyloid plaques and damaged neurons? Perhaps TREM2 variants increase the expression of pro-inflammatory molecules. Is TREM2 role in AD dependent of its interaction with ApoE? Is ApoE upstream or downstream of TREM2? It would be interesting to assess if similar TREM2 partial loss-of-function is observed in AD patients without AD-related TREM2 
risk variants. This may occur through the interaction between TREM2 and APOE or oligomeric forms of $A \beta$, both of which are able to bind TREM2 and modulate its functions. Data obtained during the last 5 years has provided many answers regarding the role of TREM2 in $\mathrm{AD}$, and has identified TREM2 as a therapeutic target. However, substantial questions regarding the potential targeting of TREM2 remain unclear. Is TREM2 beneficial or damaging at particular disease stages? The trigger of the disease? Or just a catalyst of an inevitable AD? The complexity of TREM2 in AD is beyond doubt and brings new questions with each new discovery. Addressing these questions first will be necessary to explain the role of TREM2 and microglia in AD and will help determine whether targeting it is a viable therapeutic strategy.

\begin{abstract}
Abbreviations
AAV: Adeno-associated virus; AD: Alzheimer's disease; ApoE: Apolipoprotein E; AB: Amyloid- $\beta$ peptide; ALS: Amyotrophic lateral sclerosis; CNS: Central nervous system; CSF: Cerebral spinal fluid; DAP: DNAX-activation protein; Fc: Fragment crystallizable; GSK-3 $\beta$ : Glycogen synthase kinase 3; GWAS: Genome wide association studies; HDL: High-density lipoproteins; ITAMs: Immunoreceptor tyrosine-based activation motifs; IL: Interleukin; IL$1 \beta$ : Interleukin 1 beta; JNK: c-Jun N-terminal kinase; LDL: Low-density lipoproteins; LPS: Lipopolysaccharide; LOAD: Late-onset Alzheimer's disease; LTA: Lipoteichoic acids; MAPK: Mitogen activated protein kinase; mTOR: Mammalian target of rapamycin; NOS2: NO synthase-2 transcription; NFT: Neurofibrillary tangle; PD: Parkinson's disease; PI3K: Phosphatidylinositol 3-kinase; TLR: Toll-like receptor; TREM: Triggering receptors expressed on myeloid cells; TNF-a: Tumor necrosis factor alpha
\end{abstract}

\section{Acknowledgments}

The authors would like to thank InPrint, a scientific editing network, and Elise Alspach and Angela Schlegel for assisting in editing and correcting the structure/grammar of the manuscript. The author would like to thank Servier Medical Art that provides professionally designed biological elements for figures design.

\section{Avaibility of data and materials}

Not applicable.

\section{Funding}

This review was supported by grants from the Charles and Helen Schwab Foundation $(\mathrm{DMH})$ and the Edward N. and Della L. Thome Memorial Foundation, Bank of America, N.A., Trustee (DMH).

\section{Authors' contributions}

MG reviewed the literature, drafted and revised the manuscript. MG constructed the figures. CEGL and DMH critically revised the manuscript. All authors read and approved the final manuscript.

\section{Ethics approval and consent to participate}

Not applicable.

\section{Consent for publication}

Not applicable.

\section{Competing interests}

$\mathrm{DMH}$ is listed as an inventor on a provisional patent from Washington University on TREM2 antibodies. CEGL and DMH are listed as inventors on a patent licensed by Washington University to C2N Diagnostics on the therapeutic use of anti-tau antibodies. DMH co-founded and is on the scientific advisory board of C2N Diagnostics, LLC. C2N Diagnostics, LLC has licensed certain anti-tau antibodies to AbbVie for therapeutic development. DMH is on the scientific advisory board of Proclara and Denali and consults for Genentech, AbbVie, and Idorsia.

\section{Publisher's Note}

Springer Nature remains neutral with regard to jurisdictional claims in published maps and institutional affiliations.

\section{Author details}

${ }^{1}$ Department of Neurology, St. Louis, USA. ${ }^{2}$ Hope Center for Neurological Disorders, St. Louis, USA. ${ }^{3}$ Knight Alzheimer's Disease Research Center, Washington University School of Medicine, St. Louis, MO 63110, USA.

Received: 25 October 2018 Accepted: 28 November 2018

Published online: 20 December 2018

\section{References}

1. Alzheimer A. Über eine eigenartige Erkrankung der Hirnrinde. Allgemeine Zeitschrift fur Psychiatrie und Psychisch-gerichtliche Medizin. 1907;64:146-8.

2. Alzheimer A, Stelzmann RA, Schnitzlein HN, Murtagh FR. An English translation of Alzheimer's 1907 paper, "Uber eine eigenartige Erkankung der Hirnrinde". Clin Anat. 1995;8:429-31.

3. Castellani RJ, Rolston RK, Smith MA. Alzheimer disease. Dis Mon. 2010;56: 484-546.

4. Holtzman DM, Morris JC, Goate AM. Alzheimer's disease: the challenge of the second century. Sci Transl Med. 2011;3:77sr1.

5. Serrano-Pozo A, Frosch MP, Masliah E, Hyman BT. Neuropathological alterations in Alzheimer disease. Cold Spring Harb Perspect Med. 2011;1: a006189.

6. Alzheimer's A. Alzheimer's disease facts and figures. Alzheimers Dement. 2016;2016(12):459-509.

7. Beach TG, Walker R, McGeer EG. Patterns of gliosis in Alzheimer's disease and aging cerebrum. Glia. 1989;2:420-36.

8. Itagaki S, McGeer PL, Akiyama H, Zhu S, Selkoe D. Relationship of microglia and astrocytes to amyloid deposits of Alzheimer disease. J Neuroimmunol. 1989;24:173-82.

9. McGeer PL, Itagaki S, Tago H, McGeer EG. Reactive microglia in patients with senile dementia of the Alzheimer type are positive for the histocompatibility glycoprotein HLA-DR. Neurosci Lett. 1987;79:195-200.

10. Wyss-Coray T, Mucke L. Inflammation in neurodegenerative disease--a double-edged sword. Neuron. 2002;35:419-32.

11. Wyss-Coray T, Loike JD, Brionne TC, Lu E, Anankov R, Yan F, Silverstein SC, Husemann J. Adult mouse astrocytes degrade amyloid-beta in vitro and in situ. Nat Med. 2003;9:453-7.

12. Mandrekar S, Jiang Q, Lee CY, Koenigsknecht-Talboo J, Holtzman DM, Landreth GE. Microglia mediate the clearance of soluble Abeta through fluid phase macropinocytosis. J Neurosci. 2009;29:4252-62.

13. Paresce DM, Ghosh RN, Maxfield FR. Microglial cells internalize aggregates of the Alzheimer's disease amyloid beta-protein via a scavenger receptor. Neuron. 1996;17:553-65.

14. Akiyama H, Barger S, Barnum S, Bradt B, Bauer J, Cole GM, Cooper NR, Eikelenboom P, Emmerling M, Fiebich BL, et al. Inflammation and Alzheimer's disease. Neurobiol Aging. 2000;21:383-421.

15. Calsolaro V, Edison P. Neuroinflammation in Alzheimer's disease: Current evidence and future directions. Alzheimer's \& dementia : the journal of the Alzheimer's Association. 2016;12:719-32.

16. Yoshiyama Y, Higuchi M, Zhang B, Huang SM, Iwata N, Saido TC, Maeda J, Suhara T, Trojanowski JQ, Lee VM. Synapse loss and microglial activation precede tangles in a P301S tauopathy mouse model. Neuron. 2007;53:337-51.

17. Roe AD, Staup MA, Serrats J, Sawchenko PE, Rissman RA. Lipopolysaccharide-induced tau phosphorylation and kinase activity-modulation, but not mediation, by corticotropin-releasing factor receptors. Eur J Neurosci. 2011;34:448-56.

18. Gorlovoy P, Larionov S, Pham TT, Neumann H. Accumulation of tau induced in neurites by microglial proinflammatory mediators. Faseb J. 2009;23:2502-13.

19. Harvey RJ, Skelton-Robinson M, Rossor MN. The prevalence and causes of dementia in people under the age of 65 years. J Neurol Neurosurg Psychiatry. 2003;74:1206-9.

20. Gatz M, Reynolds CA, Fratiglioni L, Johansson B, Mortimer JA, Berg S, Fiske A, Pedersen NL. Role of genes and environments for explaining Alzheimer disease. Arch Gen Psychiatry. 2006;63:168-74.

21. Karch CM, Goate AM. Alzheimer's disease risk genes and mechanisms of disease pathogenesis. Biol Psychiatry. 2015;77:43-51.

22. Corder EH, Saunders AM, Strittmatter WJ, Schmechel DE, Gaskell PC, Small GW, Roses AD, Haines JL, Pericak-Vance MA. Gene dose of apolipoprotein E 
type 4 allele and the risk of Alzheimer's disease in late onset families. Science. 1993;261:921-3.

23. Strittmatter WJ, Weisgraber KH, Huang DY, Dong LM, Salvesen GS, PericakVance M, Schmechel D, Saunders AM, Goldgaber D, Roses AD. Binding of human apolipoprotein E to synthetic amyloid beta peptide: isoform-specific effects and implications for late-onset Alzheimer disease. Proc Natl Acad Sci U S A. 1993;90:8098-102

24. Castellano JM, Kim J, Stewart FR, Jiang H, DeMattos RB, Patterson BW, Fagan AM, Morris JC, Mawuenyega KG, Cruchaga C, et al. Human apoE isoforms differentially regulate brain amyloid-beta peptide clearance. Sci Transl Med. 2011;3:89ra57.

25. Kim J, Basak JM, Holtzman DM. The role of apolipoprotein E in Alzheimer's disease. Neuron. 2009;63:287-303.

26. Verghese PB, Castellano JM, Garai K, Wang Y, Jiang H, Shah A, Bu G, Frieden C, Holtzman DM. ApoE influences amyloid-beta (Abeta) clearance despite minimal apoE/Abeta association in physiological conditions. Proc Natl Acad Sci U S A. 2013;110:E1807-16.

27. Shi Y, Yamada K, Liddelow SA, Smith ST, Zhao L, Luo W, Tsai RM, Spina S, Grinberg LT, Rojas JC, et al. ApoE4 markedly exacerbates tau-mediated neurodegeneration in a mouse model of tauopathy. Nature. 2017:549:523-7.

28. Malik M, Parikh I, Vasquez JB, Smith C, Tai L, Bu G, LaDu MJ, Fardo DW, Rebeck GW, Estus S. Genetics ignite focus on microglial inflammation in Alzheimer's disease. Mol Neurodegener. 2015;10:52.

29. Zhang ZG, Li Y, Ng CT, Song YQ. Inflammation in Alzheimer's Disease and Molecular Genetics: Recent Update. Arch Immunol Ther Exp (Warsz). 2015; 63:333-44.

30. Bouchon A, Dietrich J, Colonna M. Cutting edge: inflammatory responses can be triggered by TREM-1, a novel receptor expressed on neutrophils and monocytes. J Immunol. 2000;164:4991-5.

31. Allcock RJ, Barrow AD, Forbes S, Beck S, Trowsdale J. The human TREM gene cluster at 6p21.1 encodes both activating and inhibitory single lgV domain receptors and includes NKp44. Eur J Immunol. 2003;33:567-77.

32. Bouchon A, Hernandez-Munain C, Cella M, Colonna M. A DAP12-mediated pathway regulates expression of CC chemokine receptor 7 and maturation of human dendritic cells. J Exp Med. 2001;194:1111-22.

33. Cella M, Buonsanti C, Strader C, Kondo T, Salmaggi A, Colonna M. Impaired differentiation of osteoclasts in TREM-2-deficient individuals. J Exp Med. 2003:198:645-51.

34. Goncalves LA, Rodrigues-Duarte L, Rodo J. Vieira de Moraes L, Marques I, Penha-Goncalves C: TREM2 governs Kupffer cell activation and explains belr1 genetic resistance to malaria liver stage infection. Proc Natl Acad Sci U S A. 2013;110:19531-6.

35. Hu N, Tan MS, Yu JT, Sun L, Tan L, Wang YL, Jiang T, Tan L. Increased expression of TREM2 in peripheral blood of Alzheimer's disease patients. J Alzheimers Dis. 2014:38:497-501.

36. Humphrey MB, Daws MR, Spusta SC, Niemi EC, Torchia JA, Lanier LL, Seaman WE, Nakamura MC. TREM2, a DAP12-associated receptor, regulates osteoclast differentiation and function. J Bone Miner Res. 2006;21:237-45.

37. Koth LL, Cambier CJ, Ellwanger A, Solon M, Hou L, Lanier LL, Abram CL, Hamerman JA, Woodruff PG. DAP12 is required for macrophage recruitment to the lung in response to cigarette smoke and chemotaxis toward CCL2. J Immunol. 2010;184:6522-8.

38. Paloneva J, Mandelin J, Kiialainen A, Bohling T, Prudlo J, Hakola P, Haltia M, Konttinen YT, Peltonen L. DAP12/TREM2 deficiency results in impaired osteoclast differentiation and osteoporotic features. J Exp Med. 2003;198: 669-75

39. Sessa G, Podini P, Mariani M, Meroni A, Spreafico R, Sinigaglia F, Colonna M, Panina P, Meldolesi J. Distribution and signaling of TREM2/DAP12, the receptor system mutated in human polycystic lipomembraneous osteodysplasia with sclerosing leukoencephalopathy dementia. Eur Neurosci. 2004;20:2617-28.

40. Garcia-Alloza M, Borrelli LA, Thyssen DH, Hickman SE, El Khoury J, Bacskai BJ. Four-dimensional microglia response to anti-Abeta treatment in APP/ PS1xCX3CR1/GFP mice. Intravital. 2013;2.

41. Forabosco P, Ramasamy A, Trabzuni D, Walker R, Smith C, Bras J, Levine AP, Hardy J, Pocock JM, Guerreiro R, et al. Insights into TREM2 biology by network analysis of human brain gene expression data. Neurobiol Aging. 2013;34:2699-714.

42. Kiialainen A, Hovanes K, Paloneva J, Kopra O, Peltonen L. Dap12 and Trem2, molecules involved in innate immunity and neurodegeneration, are coexpressed in the CNS. Neurobiol Dis. 2005;18:314-22.
43. Takahashi K, Rochford CD, Neumann H. Clearance of apoptotic neurons without inflammation by microglial triggering receptor expressed on myeloid cells-2. J Exp Med. 2005;201:647-57.

44. Neumann $\mathrm{H}$, Takahashi K. Essential role of the microglial triggering receptor expressed on myeloid cells-2 (TREM2) for central nervous tissue immune homeostasis. J Neuroimmunol. 2007:184:92-9.

45. Jay TR, Miller CM, Cheng PJ, Graham LC, Bemiller S, Broihier ML, Xu G, Margevicius D, Karlo JC, Sousa GL, et al. TREM2 deficiency eliminates TREM2 + inflammatory macrophages and ameliorates pathology in Alzheimer's disease mouse models. J Exp Med. 2015;212:287-95.

46. Satoh J, Tabunoki H, Ishida T, Yagishita S, Jinnai K, Futamura N, Kobayashi M, Toyoshima I, Yoshioka T, Enomoto K, et al. Immunohistochemical characterization of microglia in Nasu-Hakola disease brains. Neuropathology. 2011;31:363-75.

47. Lue LF, Schmitz CT, Serrano G, Sue LI, Beach TG, Walker DG. TREM2 Protein Expression Changes Correlate with Alzheimer's Disease Neurodegenerative Pathologies in Post-Mortem Temporal Cortices. Brain Pathol. 2015;25:469-80.

48. Schmid CD, Sautkulis LN, Danielson PE, Cooper J, Hasel KW, Hilbush BS, Sutcliffe JG, Carson MJ. Heterogeneous expression of the triggering receptor expressed on myeloid cells-2 on adult murine microglia. J Neurochem. 2002:83:1309-20.

49. Chertoff M, Shrivastava K, Gonzalez B, Acarin L, Gimenez-Llort L. Differential modulation of TREM2 protein during postnatal brain development in mice. PLoS One. 2013;8:e72083.

50. Turnbull IR, Gilfillan S, Cella M, Aoshi T, Miller M, Piccio L, Hernandez M, Colonna M. Cutting edge: TREM-2 attenuates macrophage activation. J Immunol. 2006;177:3520-4.

51. Bhattacharjee S, Zhao Y, Dua P, Rogaev El, Lukiw WJ. microRNA-34aMediated Down-Regulation of the Microglial-Enriched Triggering Receptor and Phagocytosis-Sensor TREM2 in Age-Related Macular Degeneration. PLoS One. 2016;11:e0150211.

52. Zheng H, Liu CC, Atagi Y, Chen XF, Jia L, Yang L, He W, Zhang X, Kang SS, Rosenberry $T L$, et al. Opposing roles of the triggering receptor expressed on myeloid cells 2 and triggering receptor expressed on myeloid cells-like transcript 2 in microglia activation. Neurobiol Aging. 2016;42:132-41.

53. Liu G, Liu Y, Jiang Q, Jiang Y, Feng R, Zhang L, Chen Z, Li K, Liu J. Convergent Genetic and Expression Datasets Highlight TREM2 in Parkinson's Disease Susceptibility. Mol Neurobiol. 2016;53:4931-8.

54. Cady J, Koval ED, Benitez BA, Zaidman C, Jockel-Balsarotti J, Allred P, Baloh RH, Ravits J, Simpson E, Appel SH, et al. TREM2 variant p.R47H as a risk factor for sporadic amyotrophic lateral sclerosis. JAMA Neurol. 2014;71:449-53.

55. Kawabori M, Kacimi R, Kauppinen T, Calosing C, Kim JY, Hsieh CL, Nakamura MC, Yenari MA. Triggering receptor expressed on myeloid cells 2 (TREM2) deficiency attenuates phagocytic activities of microglia and exacerbates ischemic damage in experimental stroke. J Neurosci. 2015;35:3384-96.

56. Saber M, Kokiko-Cochran O, Puntambekar SS, Lathia JD, Lamb BT. Triggering Receptor Expressed on Myeloid Cells 2 Deficiency Alters Acute Macrophage Distribution and Improves Recovery after Traumatic Brain Injury. J Neurotrauma. 2017;34:423-35.

57. Celarain N, Sanchez-Ruiz de Gordoa J, Zelaya MV, Roldan M, Larumbe R, Pulido L, Echavarri C, Mendioroz M. TREM2 upregulation correlates with 5hydroxymethycytosine enrichment in Alzheimer's disease hippocampus. Clin Epigenetics. 2016:8:37.

58. Ma L, Allen M, Sakae N, Ertekin-Taner N, Graff-Radford NR, Dickson DW, Younkin SG, Sevlever D. Expression and processing analyses of wild type and p.R47H TREM2 variant in Alzheimer's disease brains. Mol Neurodegener. 2016:11:72.

59. Perez SE, Nadeem M, He B, Miguel JC, Malek-Ahmadi MH, Chen K, Mufson EJ. Neocortical and hippocampal TREM2 protein levels during the progression of Alzheimer's disease. Neurobiol Aging. 2017;54:133-43.

60. Raha AA, Henderson JW, Stott SR, Vuono R, Foscarin S, Friedland RP, Zaman $\mathrm{SH}$, Raha-Chowdhury R. Neuroprotective Effect of TREM-2 in Aging and Alzheimer's Disease Model. J Alzheimers Dis. 2017;55:199-217.

61. Matarin M, Salih DA, Yasvoina M, Cummings DM, Guelfi S, Liu W, Nahaboo Solim MA, Moens TG, Paublete RM, Ali SS, et al. A genome-wide geneexpression analysis and database in transgenic mice during development of amyloid or tau pathology. Cell Rep. 2015;10:633-44.

62. Savage JC, Jay T, Goduni E, Quigley C, Mariani MM, Malm T, Ransohoff RM, Lamb BT, Landreth GE. Nuclear receptors license phagocytosis by trem2+ myeloid cells in mouse models of Alzheimer's disease. J Neurosci. 2015;35: 6532-43. 
63. Jiang T, Tan L, Zhu XC, Zhang QQ, Cao L, Tan MS, Gu LZ, Wang HF, Ding ZZ, Zhang YD, Yu JT. Upregulation of TREM2 ameliorates neuropathology and rescues spatial cognitive impairment in a transgenic mouse model of Alzheimer's disease. Neuropsychopharmacology. 2014;39:2949-62.

64. Yeh FL, Hansen DV, Sheng M. TREM2, Microglia, and Neurodegenerative Diseases. Trends Mol Med. 2017;23:512-33.

65. Daws MR, Lanier LL, Seaman WE, Ryan JC. Cloning and characterization of a novel mouse myeloid DAP12-associated receptor family. Eur J Immunol. 2001;31:783-91.

66. Lanier LL, Corliss BC, Wu J, Leong C, Phillips JH. Immunoreceptor DAP12 bearing a tyrosine-based activation motif is involved in activating NK cells. Nature. 1998;391:703-7.

67. Call ME, Wucherpfennig KW, Chou JJ. The structural basis for intramembrane assembly of an activating immunoreceptor complex. Nat Immunol. 2010;11:1023-9.

68. Mocsai A, Ruland J, Tybulewicz VL. The SYK tyrosine kinase: a crucial player in diverse biological functions. Nat Rev Immunol. 2010;10:387-402.

69. Sada K, Takano T, Yanagi S, Yamamura H. Structure and function of Syk protein-tyrosine kinase. J Biochem. 2001;130:177-86.

70. Sun M, Zhu M, Chen K, Nie X, Deng Q, Hazlett LD, Wu Y, Li M, Wu M, Huang $X$. TREM-2 promotes host resistance against Pseudomonas aeruginosa infection by suppressing corneal inflammation via a PI3K/Akt signaling pathway. Invest Ophthalmol Vis Sci. 2013;54:3451-62.

71. Peng Q, Malhotra S, Torchia JA, Kerr WG, Coggeshall KM, Humphrey MB. TREM2- and DAP12-dependent activation of PI3K requires DAP10 and is inhibited by SHIP1. Sci Signal. 2010;3:ra38.

72. Daws MR, Sullam PM, Niemi EC, Chen TT, Tchao NK, Seaman WE. Pattern recognition by TREM-2: binding of anionic ligands. J Immunol. 2003;171: 594-9.

73. Cannon JP, O'Driscoll M, Litman GW. Specific lipid recognition is a general feature of CD300 and TREM molecules. Immunogenetics. 2012;64:39-47.

74. Kober DL, Alexander-Brett JM, Karch CM, Cruchaga C, Colonna M, Holtzman MJ, Brett TJ. Neurodegenerative disease mutations in TREM2 reveal a functional surface and distinct loss-of-function mechanisms. Elife. 2016;5.

75. Wang Y, Cella M, Mallinson K, Ulrich JD, Young KL, Robinette ML, Gilfillan S, Krishnan GM, Sudhakar S, Zinselmeyer BH, et al. TREM2 lipid sensing sustains the microglial response in an Alzheimer's disease model. Cell. 2015; 160:1061-71.

76. Yeh FL, Wang Y, Tom I, Gonzalez LC, Sheng M. TREM2 Binds to Apolipoproteins, Including APOE and CLU/APOJ, and Thereby Facilitates Uptake of Amyloid-Beta by Microglia. Neuron. 2016;91:328-40.

77. Song W, Hooli B, Mullin K, Jin SC, Cella M, Ulland TK, Wang Y, Tanzi RE, Colonna M. Alzheimer's disease-associated TREM2 variants exhibit either decreased or increased ligand-dependent activation. Alzheimers Dement. 2017;13:381-7.

78. Atagi $Y$, Liu CC, Painter MM, Chen XF, Verbeeck C, Zheng H, Li X, Rademakers R, Kang SS, Xu H, et al. Apolipoprotein E Is a Ligand for Triggering Receptor Expressed on Myeloid Cells 2 (TREM2). J Biol Chem. 2015;290:26043-50.

79. Bailey CC, DeVaux LB, Farzan M. The Triggering Receptor Expressed on Myeloid Cells 2 Binds Apolipoprotein E. J Biol Chem. 2015;290:26033-42.

80. Jendresen C, Arskog V, Daws MR, Nilsson LN. The Alzheimer's disease risk factors apolipoprotein E and TREM2 are linked in a receptor signaling pathway. J Neuroinflammation. 2017;14:59.

81. Zhao $Y$, Wu X, Li X, Jiang LL, Gui X, Liu Y, Sun Y, Zhu B, Pina-Crespo JC, Zhang $M$, et al. TREM2 Is a Receptor for beta-Amyloid that Mediates Microglial Function. Neuron. 2018;97:1023-31 e1027.

82. Ulrich JD, Ulland TK, Mahan TE, Nystrom S, Nilsson KP, Song WM, Zhou Y, Reinartz $M$, Choi $S$, Jiang $H$, et al. ApoE facilitates the microglial response to amyloid plaque pathology. J Exp Med. 2018;215:1047-58.

83. Hsieh CL, Koike M, Spusta SC, Niemi EC, Yenari M, Nakamura MC, Seaman WE. A role for TREM2 ligands in the phagocytosis of apoptotic neuronal cells by microglia. J Neurochem. 2009;109:1144-56.

84. Gawish R, Martins R, Bohm B, Wimberger T, Sharif O, Lakovits K, Schmidt M, Knapp S. Triggering receptor expressed on myeloid cells-2 fine-tunes inflammatory responses in murine Gram-negative sepsis. FASEB J. 2015;29: 1247-57.

85. Kleinberger G, Yamanishi $Y$, Suarez-Calvet M, Czirr E, Lohmann E, Cuyvers E, Struyfs H, Pettkus N, Wenninger-Weinzierl A, Mazaheri F, et al. TREM2 mutations implicated in neurodegeneration impair cell surface transport and phagocytosis. Sci Transl Med. 2014;6:243ra286.
86. Stefano L, Racchetti G, Bianco F, Passini N, Gupta RS, Panina Bordignon P, Meldolesi J. The surface-exposed chaperone, Hsp60, is an agonist of the microglial TREM2 receptor. J Neurochem. 2009;110:284-94.

87. N'Diaye EN, Branda CS, Branda SS, Nevarez L, Colonna M, Lowell C, Hamerman JA, Seaman WE. TREM-2 (triggering receptor expressed on myeloid cells 2) is a phagocytic receptor for bacteria. J Cell Biol. 2009;184: 215-23.

88. Takahashi K, Prinz M, Stagi M, Chechneva O, Neumann H. TREM2-transduced myeloid precursors mediate nervous tissue debris clearance and facilitate recovery in an animal model of multiple sclerosis. PLoS Med. 2007;4:e124.

89. Wang $Y$, Ulland TK, Ulrich JD, Song W, Tzaferis JA, Hole JT, Yuan P, Mahan TE, Shi Y, Gilfillan S, et al. TREM2-mediated early microglial response limits diffusion and toxicity of amyloid plaques. J Exp Med. 2016;213:667-75.

90. Yuan P, Condello C, Keene CD, Wang Y, Bird TD, Paul SM, Luo W, Colonna M, Baddeley D, Grutzendler J. TREM2 Haplodeficiency in Mice and Humans Impairs the Microglia Barrier Function Leading to Decreased Amyloid Compaction and Severe Axonal Dystrophy. Neuron. 2016;90:724-39.

91. Hamerman JA, Tchao NK, Lowell CA, Lanier LL. Enhanced Toll-like receptor responses in the absence of signaling adaptor DAP12. Nat Immunol. 2005;6: 579-86.

92. Gao $X$, Dong $Y$, Liu Z, Niu B. Silencing of triggering receptor expressed on myeloid cells-2 enhances the inflammatory responses of alveolar macrophages to lipopolysaccharide. Mol Med Rep. 2013;7:921-6.

93. Zhong L, Chen XF, Zhang ZL, Wang Z, Shi XZ, Xu K, Zhang YW, Xu H, Bu G. DAP12 Stabilizes the C-terminal Fragment of the Triggering Receptor Expressed on Myeloid Cells-2 (TREM2) and Protects against LPS-induced Pro-inflammatory Response. J Biol Chem. 2015;290:15866-77.

94. Piccio L, Buonsanti C, Mariani M, Cella M, Gilfillan S, Cross AH, Colonna M, Panina-Bordignon P. Blockade of TREM-2 exacerbates experimental autoimmune encephalomyelitis. Eur J Immunol. 2007;37:1290-301.

95. Krasemann S, Madore C, Cialic R, Baufeld C, Calcagno N, El Fatimy R, Beckers L, O'Loughlin E, Xu Y, Fanek Z, et al. The TREM2-APOE Pathway Drives the Transcriptional Phenotype of Dysfunctional Microglia in Neurodegenerative Diseases. Immunity. 2017:47:566-81 e569.

96. Kobayashi M, Konishi H, Sayo A, Takai T, Kiyama H. TREM2/DAP12 Signal Elicits Proinflammatory Response in Microglia and Exacerbates Neuropathic Pain. J Neurosci. 2016;36:11138-50.

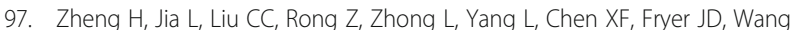
$X$, Zhang YW, et al. TREM2 Promotes Microglial Survival by Activating Wnt/ beta-Catenin Pathway. J Neurosci. 2017;37:1772-84.

98. Seno H, Miyoshi H, Brown SL, Geske MJ, Colonna M, Stappenbeck TS. Efficient colonic mucosal wound repair requires Trem2 signaling. Proc Natl Acad Sci U S A. 2009;106:256-61.

99. Wu K, Byers DE, Jin X, Agapov E, Alexander-Brett J, Patel AC, Cella M, Gilfilan $\mathrm{S}$, Colonna M, Kober DL, et al. TREM-2 promotes macrophage survival and lung disease after respiratory viral infection. J Exp Med. 2015;212:681-97.

100. Bianchin MM, Capella HM, Chaves DL, Steindel M, Grisard EC, Ganev GG, da Silva Junior JP, Neto Evaldo S, Poffo MA, Walz R, et al. Nasu-Hakola disease (polycystic lipomembranous osteodysplasia with sclerosing leukoencephalopathy--PLOSL): a dementia associated with bone cystic lesions. From clinical to genetic and molecular aspects. Cell Mol Neurobiol. 2004; $24: 1-24$.

101. Paloneva J, Manninen T, Christman G, Hovanes K, Mandelin J, Adolfsson R, Bianchin M, Bird T, Miranda R, Salmaggi A, et al. Mutations in two genes encoding different subunits of a receptor signaling complex result in an identical disease phenotype. Am J Hum Genet. 2002;71:656-62.

102. Lill CM, Rengmark A, Pihlstrom L, Fogh I, Shatunov A, Sleiman PM, Wang LS, Liu T, Lassen CF, Meissner E, et al. The role of TREM2 R47H as a risk factor for Alzheimer's disease, frontotemporal lobar degeneration, amyotrophic lateral sclerosis, and Parkinson's disease. Alzheimers Dement. 2015;11:1407-16.

103. Rayaprolu S, Mullen B, Baker M, Lynch T, Finger E, Seeley WW, Hatanpaa K, Lomen-Hoerth C, Kertesz A, Bigio EH, et al. TREM2 in neurodegeneration: evidence for association of the p.R47H variant with frontotemporal dementia and Parkinson's disease. Mol Neurodegener. 2013;8:19.

104. Ruiz A, Dols-Icardo O, Bullido MJ, Pastor P, Rodriguez-Rodriguez E, Lopez de Munain A, de Pancorbo MM, Perez-Tur J, Alvarez V, Antonell A, et al. Assessing the role of the TREM2 p.R47H variant as a risk factor for Alzheimer's disease and frontotemporal dementia. Neurobiol Aging. 2014; 35(444):e441-4.

105. Cuyvers E, Bettens K, Philtjens S, Van Langenhove T, Gijselinck I, van der Zee J, Engelborghs S, Vandenbulcke M, Van Dongen J, Geerts N, et al. 
Investigating the role of rare heterozygous TREM2 variants in Alzheimer's disease and frontotemporal dementia. Neurobiol Aging. 2014;35(726):e711-29.

106. Lattante S, Le Ber I, Camuzat A, Dayan S, Godard C, Van Bortel I, De Septenville A, Ciura S, Brice A, Kabashi E, et al. TREM2 mutations are rare in a French cohort of patients with frontotemporal dementia. Neurobiol Aging. 2013;34(2443):e2441-2.

107. Slattery CF, Beck JA, Harper L, Adamson G, Abdi Z, Uphill J, Campbell T, Druyeh R, Mahoney CJ, Rohrer JD, et al. R47H TREM2 variant increases risk of typical early-onset Alzheimer's disease but not of prion or frontotemporal dementia. Alzheimers Dement. 2014;10:602-8 e604.

108. Guerreiro R, Wojtas A, Bras J, Carrasquillo M, Rogaeva E, Majounie E, Cruchaga C, Sassi C, Kauwe JS, Younkin S, et al. TREM2 variants in Alzheimer's disease. N Engl J Med. 2013;368:117-27.

109. Jonsson T, Stefansson H, Steinberg S, Jonsdottir I, Jonsson PV, Snaedal J, Bjornsson S, Huttenlocher J, Levey Al, Lah JJ, et al. Variant of TREM2 associated with the risk of Alzheimer's disease. N Engl J Med. 2013;368:107-16.

110. Benitez BA, Cooper B, Pastor P, Jin SC, Lorenzo E, Cervantes S, Cruchaga C. TREM2 is associated with the risk of Alzheimer's disease in Spanish population. Neurobiol Aging. 2013;34(1711):e1715-7.

111. Finelli D, Rollinson S, Harris J, Jones M, Richardson A, Gerhard A, Snowden J, Mann D, Pickering-Brown S. TREM2 analysis and increased risk of Alzheimer's disease. Neurobiol Aging. 2015;36(546):e549-13.

112. Ghani M, Sato C, Kakhki EG, Gibbs JR, Traynor B, St George-Hyslop P, Rogaeva E. Mutation analysis of the MS4A and TREM gene clusters in a case-control Alzheimer's disease data set. Neurobiol Aging. 2016;42(217):e217-3.

113. Gonzalez Murcia JD, Schmutz C, Munger C, Perkes A, Gustin A, Peterson M, Ebbert MT, Norton MC, Tschanz JT, Munger RG, et al. Assessment of TREM2 rs75932628 association with Alzheimer's disease in a population-based sample: the Cache County Study. Neurobiol Aging. 2013;34(2889):e2811-83.

114. Hooli BV, Parrado AR, Mullin K, Yip WK, Liu T, Roehr JT, Qiao D, Jessen F, Peters $\mathrm{O}$, Becker $\mathrm{T}$, et al. The rare TREM2 R47H variant exerts only a modest effect on Alzheimer disease risk. Neurology. 2014:83:1353-8.

115. Jin SC, Benitez BA, Karch CM, Cooper B, Skorupa T, Carrell D, Norton JB, Hsu S, Harari O, Cai $Y$, et al. Coding variants in TREM2 increase risk for Alzheimer's disease. Hum Mol Genet. 2014;23:5838-46.

116. Pottier C, Wallon D, Rousseau S, Rovelet-Lecrux A, Richard AC, Rollin-Sillaire A, Frebourg T, Campion D, Hannequin D. TREM2 R47H variant as a risk factor for early-onset Alzheimer's disease. J Alzheimers Dis. 2013;35:45-9.

117. Rosenthal SL, Bamne MN, Wang X, Berman S, Snitz BE, Klunk WE, Sweet RA, Demirci FY, Lopez OL, Kamboh MI. More evidence for association of a rare TREM2 mutation (R47H) with Alzheimer's disease risk. Neurobiol Aging. 2015;36(2443):e2421-46.

118. Sims R, van der Lee SJ, Naj AC, Bellenguez C, Badarinarayan N, Jakobsdottir J, Kunkle BW, Boland A, Raybould R, Bis JC, et al. Rare coding variants in PLCG2, ABI3, and TREM2 implicate microglial-mediated innate immunity in Alzheimer's disease. Nat Genet. 2017:49:1373-84.

119. Yu JT, Jiang $T$, Wang $Y L$, Wang HF, Zhang W, Hu N, Tan L, Sun L, Tan MS, Zhu XC, Tan $L$. Triggering receptor expressed on myeloid cells 2 variant is rare in late-onset Alzheimer's disease in Han Chinese individuals. Neurobiol Aging. 2014;35(937):e931-3.

120. Wang P, Guo Q, Zhou Y, Chen K, Xu Y, Ding D, Hong Z, Zhao Q. Lack of association between triggering receptor expressed on myeloid cells 2 polymorphism rs75932628 and late-onset Alzheimer's disease in a Chinese Han population. Psychiatr Genet. 2018;28:16-8.

121. Ma J, Zhou Y, Xu J, Liu X, Wang Y, Deng Y, Wang G, Xu W, Ren R, Liu X, et al. Association study of TREM2 polymorphism rs75932628 with late-onset Alzheimer's disease in Chinese Han population. Neurol Res. 2014;36:894-6.

122. Jiao B, Liu X, Tang B, Hou L, Zhou L, Zhang F, Zhou Y, Guo J, Yan X, Shen L. Investigation of TREM2, PLD3, and UNC5C variants in patients with Alzheimer's disease from mainland China. Neurobiol Aging. 2014;35(2422): e2429-2 e2411.

123. Jin SC, Carrasquillo MM, Benitez BA, Skorupa T, Carrell D, Patel D, Lincoln S, Krishnan S, Kachadoorian M, Reitz C, et al. TREM2 is associated with increased risk for Alzheimer's disease in African Americans. Mol Neurodegener. 2015;10:19.

124. Del-Aguila JL, Fernandez MV, Schindler S, Ibanez L, Deming Y, Ma S, Saef B, Black K, Budde J, Norton J, et al. Assessment of the Genetic Architecture of Alzheimer's Disease Risk in Rate of Memory Decline. J Alzheimers Dis. 2018; 62:745-56.

125. Korvatska O, Leverenz JB, Jayadev S, McMillan P, Kurtz I, Guo X, Rumbaugh M, Matsushita M, Girirajan S, Dorschner MO, et al. R47H Variant of TREM2
Associated With Alzheimer Disease in a Large Late-Onset Family: Clinical, Genetic, and Neuropathological Study. JAMA Neurol. 2015;72:920-7.

126. Roussos P, Katsel P, Fam P, Tan W, Purohit DP, Haroutunian V. The triggering receptor expressed on myeloid cells 2 (TREM2) is associated with enhanced inflammation, neuropathological lesions and increased risk for Alzheimer's dementia. Alzheimers Dement. 2015;11:1163-70.

127. Melchior B, Garcia AE, Hsiung BK, Lo KM, Doose JM, Thrash JC, Stalder AK, Staufenbiel M, Neumann H, Carson MJ. Dual induction of TREM2 and tolerance-related transcript, Tmem176b, in amyloid transgenic mice: implications for vaccine-based therapies for Alzheimer's disease. ASN Neuro. 2010:2:e00037.

128. Radde R, Bolmont T, Kaeser SA, Coomaraswamy J, Lindau D, Stoltze L, Calhoun ME, Jaggi F, Wolburg H, Gengler S, et al. Abeta42-driven cerebral amyloidosis in transgenic mice reveals early and robust pathology. EMBO Rep. 2006;7:940-6.

129. Oakley H, Cole SL, Logan S, Maus E, Shao P, Craft J, Guillozet-Bongaarts A, Ohno M, Disterhoft J, Van Eldik L, et al. Intraneuronal beta-amyloid aggregates, neurodegeneration, and neuron loss in transgenic mice with five familial Alzheimer's disease mutations: potential factors in amyloid plaque formation. J Neurosci. 2006;26:10129-40.

130. Ulrich JD, Finn MB, Wang $Y$, Shen A, Mahan TE, Jiang H, Stewart FR, Piccio L, Colonna M, Holtzman DM. Altered microglial response to Abeta plaques in APPPS1-21 mice heterozygous for TREM2. Mol Neurodegener. 2014;9:20.

131. Jay TR, Hirsch AM, Broihier ML, Miller CM, Neilson LE, Ransohoff RM, Lamb BT, Landreth GE. Disease Progression-Dependent Effects of TREM2 Deficiency in a Mouse Model of Alzheimer's Disease. J Neurosci. 2017;37: 637-47.

132. Song WM, Joshita S, Zhou Y, Ulland TK, Gilfillan S, Colonna M. Humanized TREM2 mice reveal microglia-intrinsic and -extrinsic effects of R47H polymorphism. J Exp Med. 2018;215:745-60.

133. Cheng-Hathaway PJ, Reed-Geaghan EG, Jay TR, Casali BT, Bemiller SM, Puntambekar SS, von Saucken VE, Williams RY, Karlo JC, Moutinho M, et al. The Trem2 R47H variant confers loss-of-function-like phenotypes in Alzheimer's disease. Mol Neurodegener. 2018;13:29.

134. Ulland TK, Song WM, Huang SC, Ulrich JD, Sergushichev A, Beatty WL, Loboda AA, Zhou Y, Cairns NJ, Kambal A, et al. TREM2 Maintains Microglial Metabolic Fitness in Alzheimer's Disease. Cell. 2017;170:649-63 e613.

135. Lee CYD, Daggett A, Gu X, Jiang LL, Langfelder P, Li X, Wang N, Zhao Y, Park CS, Cooper Y, et al. Elevated TREM2 Gene Dosage Reprograms Microglia Responsivity and Ameliorates Pathological Phenotypes in Alzheimer's Disease Models. Neuron. 2018:97:1032-48 e1035.

136. Yuan P, Condello C, Keene CD, Wang Y, Bird TD, Paul SM, Luo W, Colonna M, Baddeley D, Grutzendler J. TREM2 Haplodeficiency in Mice and Humans Impairs the Microglia Barrier Function Leading to Decreased Amyloid Compaction and Severe Axonal Dystrophy. Neuron. 2016;92:252-64.

137. Zhong L, Wang Z, Wang D, Wang Z, Martens YA, Wu L, Xu Y, Wang K, Li J, Huang $R$, et al. Amyloid-beta modulates microglial responses by binding to the triggering receptor expressed on myeloid cells 2 (TREM2). Mol Neurodegener. 2018;13:15.

138. Xiang X, Piers TM, Wefers B, Zhu K, Mallach A, Brunner B, Kleinberger G, Song W, Colonna M, Herms J, et al. The Trem2 R47H Alzheimer's risk variant impairs splicing and reduces Trem 2 mRNA and protein in mice but not in humans. Mol Neurodegener. 2018;13:49.

139. Piccio L, Deming Y, Del-Aguila JL, Ghezzi L, Holtzman DM, Fagan AM, Fenoglio C, Galimberti D, Borroni B, Cruchaga C. Cerebrospinal fluid soluble TREM2 is higher in Alzheimer disease and associated with mutation status. Acta Neuropathol. 2016:131:925-33.

140. Cruchaga C, Kauwe JS, Harari O, Jin SC, Cai Y, Karch CM, Benitez BA, Jeng AT, Skorupa T, Carrell D, et al. GWAS of cerebrospinal fluid tau levels identifies risk variants for Alzheimer's disease. Neuron. 2013;78:256-68.

141. Buerger K, Ewers M, Pirttila T, Zinkowski R, Alafuzoff I, Teipel SJ, DeBernardis J, Kerkman D, McCulloch C, Soininen H, Hampel H. CSF phosphorylated tau protein correlates with neocortical neurofibrillary pathology in Alzheimer's disease. Brain. 2006;129:3035-41.

142. Andersson C, Blennow K, Almkvist O, Andreasen N, Engfeldt P, Johansson SE, Lindau M, Eriksdotter-Jonhagen M. Increasing CSF phospho-tau levels during cognitive decline and progression to dementia. Neurobiol Aging. 2008:29:1466-73.

143. de Leon MJ, DeSanti S, Zinkowski R, Mehta PD, Pratico D, Segal S, Clark C, Kerkman D, DeBernardis J, Li J, et al. MRI and CSF studies in the early diagnosis of Alzheimer's disease. J Intern Med. 2004;256:205-23. 
144. Cherry JD, Tripodis Y, Alvarez VE, Huber B, Kiernan PT, Daneshvar DH, Mez J, Montenigro PH, Solomon TM, Alosco ML, et al. Microglial neuroinflammation contributes to tau accumulation in chronic traumatic encephalopathy. Acta Neuropathol Commun. 2016;4:112.

145. Luo W, Liu W, Hu X, Hanna M, Caravaca A, Paul SM. Microglial internalization and degradation of pathological tau is enhanced by an antitau monoclonal antibody. Sci Rep. 2015;5:11161.

146. Maphis N, Xu G, Kokiko-Cochran ON, Jiang S, Cardona A, Ransohoff RM, Lamb BT, Bhaskar K. Reactive microglia drive tau pathology and contribute to the spreading of pathological tau in the brain. Brain. 2015;138:1738-55.

147. Asai H, Ikezu S, Tsunoda S, Medalla M, Luebke J, Haydar T, Wolozin B, Butovsky O, Kugler S, Ikezu T. Depletion of microglia and inhibition of exosome synthesis halt tau propagation. Nat Neurosci. 2015;18:1584-93.

148. Jiang Y, Li Z, Ma H, Cao X, Liu F, Tian A, Sun X, Li X, Wang J. Upregulation of TREM2 Ameliorates Neuroinflammatory Responses and Improves Cognitive Deficits Triggered by Surgical Trauma in Appswe/PS1dE9 Mice. Cell Physiol Biochem. 2018;46:1398-411.

149. Jiang T, Zhang YD, Chen Q, Gao Q, Zhu XC, Zhou JS, Shi JQ, Lu H, Tan L, Yu JT. TREM2 modifies microglial phenotype and provides neuroprotection in P301S tau transgenic mice. Neuropharmacology. 2016;105:196-206.

150. Jiang T, Tan L, Zhu XC, Zhou JS, Cao L, Tan MS, Wang HF, Chen Q, Zhang YD, YU JT. Silencing of TREM2 exacerbates tau pathology, neurodegenerative changes, and spatial learning deficits in P301S tau transgenic mice. Neurobiol Aging. 2015;36:3176-86.

151. Bemiller SM, McCray TJ, Allan K, Formica SV, Xu G, Wilson G, Kokiko-Cochran ON, Crish SD, Lasagna-Reeves CA, Ransohoff RM, et al. TREM2 deficiency exacerbates tau pathology through dysregulated kinase signaling in a mouse model of tauopathy. Mol Neurodegener. 2017;12:74.

152. Leyns CEG, Ulrich JD, Finn MB, Stewart FR, Koscal LJ, Remolina Serrano J, Robinson GO, Anderson E, Colonna M, Holtzman DM. TREM2 deficiency attenuates neuroinflammation and protects against neurodegeneration in a mouse model of tauopathy. Proc Natl Acad Sci U S A. 2017;114:11524-9.

153. Sayed FA, Telpoukhovskaia M, Kodama L, Li Y, Zhou Y, Le D, Hauduc A, Ludwig C, Gao F, Clelland C, et al. Differential effects of partial and complete loss of TREM2 on microglial injury response and tauopathy. Proc Natl Acad Sci U S A. 2018;115:10172-7.

154. Andorfer C, Kress Y, Espinoza M, de Silva R, Tucker KL, Barde YA, Duff K, Davies $P$. Hyperphosphorylation and aggregation of tau in mice expressing normal human tau isoforms. J Neurochem. 2003;86:582-90.

155. Sekiya M, Wang M, Fujisaki N, Sakakibara Y, Quan X, Ehrlich ME, De Jager $P L$ Bennett DA, Schadt EE, Gandy S, et al. Integrated biology approach reveals molecular and pathological interactions among Alzheimer's Abeta42, Tau, TREM2, and TYROBP in Drosophila models. Genome Med. 2018;10:26.

156. Jiang T, Zhang YD, Gao Q, Ou Z, Gong PY, Shi JQ, Wu L, Zhou JS. TREM2 Ameliorates Neuronal Tau Pathology Through Suppression of Microglial Inflammatory Response. Inflammation. 2018;41:811-23.

157. Guerreiro R, Bras J, Hardy J. SnapShot: genetics of Alzheimer's disease. Cell. 2013;155:968 e961.

158. Casati M, Ferri E, Gussago C, Mazzola P, Abbate C, Bellelli G, Mari D, Cesari M, Arosio B. Increased expression of TREM2 in peripheral cells from mild cognitive impairment patients who progress into Alzheimer's disease. Eur J Neurol. 2018;25:805-10.

159. Li X, Montine KS, Keene CD, Montine TJ. Different mechanisms of apolipoprotein $\mathrm{E}$ isoform-dependent modulation of prostaglandin E2 production and triggering receptor expressed on myeloid cells 2 (TREM2) expression after innate immune activation of microglia. FASEB J. 2015;29: $1754-62$.

160. Murray CE, King A, Troakes C, Hodges A, Lashley T. APOE epsilon4 is also required in TREM2 R47H variant carriers for Alzheimer's disease to develop. Neuropathol Appl Neurobiol. 2018.

161. Mazaheri F, Snaidero N, Kleinberger G, Madore C, Daria A, Werner G, Krasemann S, Capell A, Trumbach D, Wurst W, et al. TREM2 deficiency impairs chemotaxis and microglial responses to neuronal injury. EMBO Rep. 2017;18:1186-98.

162. Butovsky O, Jedrychowski MP, Moore CS, Cialic R, Lanser AJ, Gabriely G, Koeglsperger T, Dake B, Wu PM, Doykan CE, et al. Identification of a unique TGF-beta-dependent molecular and functional signature in microglia. Nat Neurosci. 2014;17:131-43.

163. Zemek F, Drtinova L, Nepovimova E, Sepsova V, Korabecny J, Klimes J, Kuca K. Outcomes of Alzheimer's disease therapy with acetylcholinesterase inhibitors and memantine. Expert Opin Drug Saf. 2014;13:759-74.
164. Cuyvers E, Sleegers K. Genetic variations underlying Alzheimer's disease: evidence from genome-wide association studies and beyond. Lancet Neurol. 2016;15:857-68.

165. Xiang X, Werner G, Bohrmann B, Liesz A, Mazaheri F, Capell A, Feederle R, Knuesel I, Kleinberger G, Haass C. TREM2 deficiency reduces the efficacy of immunotherapeutic amyloid clearance. EMBO Mol Med. 2016;8:992-1004.

166. Tremblay ME, Stevens B, Sierra A, Wake H, Bessis A, Nimmerjahn A. The role of microglia in the healthy brain. J Neurosci. 2011;31:16064-9.

\section{Ready to submit your research? Choose BMC and benefit from:}

- fast, convenient online submission

- thorough peer review by experienced researchers in your field

- rapid publication on acceptance

- support for research data, including large and complex data types

- gold Open Access which fosters wider collaboration and increased citations

- maximum visibility for your research: over $100 \mathrm{M}$ website views per year

At BMC, research is always in progress.

Learn more biomedcentral.com/submissions 